OECD Guidance on Pesticide Compliance and Enforcement Best Practices
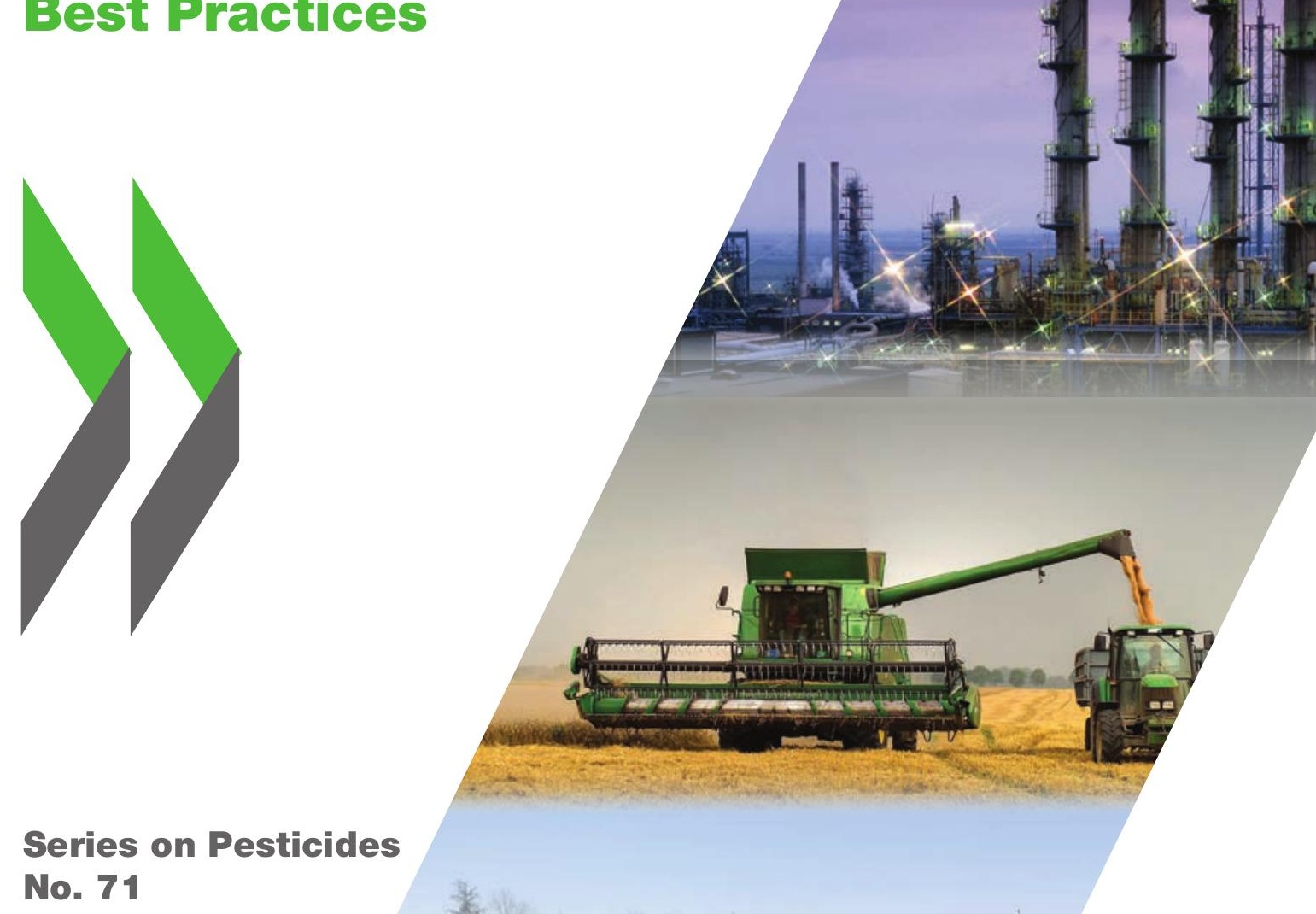

Series on Pesticides No. 71

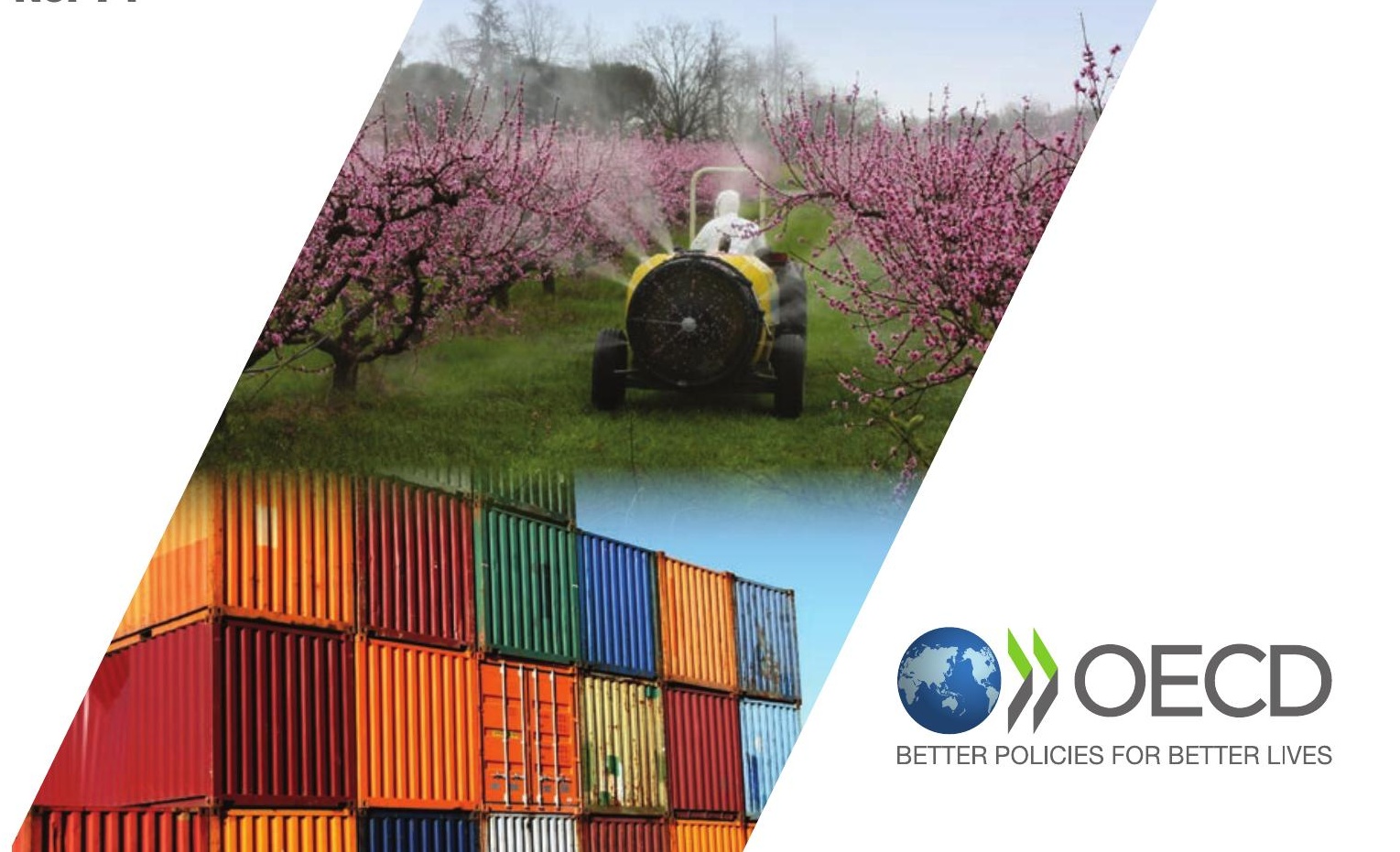


OECD Environment, Health and Safety Publications

Series on Pesticides

No. 71

\section{OECD Guidance \\ on Pesticide Compliance and Enforcement Best Practices}


Please cite this publication as:

OECD(2012), OECD Guidance on Pesticide Compliance and Enforcement Best Practices, Series on Pesticides No. 71, Environment, Health and Safety, Environment Directorate, OECD.

Note:

This publication was originally published on 19 October 2012, under the reference ENV/JM/MONO(2012)35. Minor editing and formatting amendments have been made during the preparation of this book version.

Photo credits: Cover illustrations (from top to bottom):

(C) Getty Images

(C) TSpider - Fotolia

(C) Ermess - Fotolia

(C) Claude Beaubien - Fotolia 


\section{Also published in the Series on Pesticides}

No. 1 Data Requirements for Pesticide Registration in OECD Member Countries: Survey Results (1993)

No. 2 Final Report on the OECD Pilot Project to Compare Pesticide Data Reviews (1995)

No. 3 Data Requirements for Biological Pesticides (1996)

No. 4 Activities to Reduce Pesticide Risks in OECD and Selected FAO Countries. Part I: Summary Report (1996)

No. 5 Activities to Reduce Pesticide Risks in OECD and Selected FAO Countries. Part II: Survey Responses (1996)

No. 6 OECD Governments' Approaches to the Protection of Proprietary Rights and Confidential Business Information in Pesticide Registration (1998)

No. 7 OECD Survey on the Collection and Use of Agricultural Pesticide Sales Data: Survey Results (1999) [see also No.47]

No. 8 Report of the OECD/FAO Workshop on Integrated Pest Management and Pesticide Risk Reduction (1999)

No. 9 Report of the Survey of OECD Member Countries' Approaches to the Regulation of Biocides (1999)

No. 10 Guidance Notes for Analysis and Evaluation of Repeat-Dose Toxicity Studies (2000)

No. 11 Survey of Best Practices in the Regulation of Pesticides in Twelve OECD Countries (2001)

No. 12 Guidance for Registration Requirements for Pheromones and Other Semiochemicals Used for Arthropod Pest Control (2001)

No. 13 Report of the OECD Workshop on Sharing the Work of Agricultural Pesticide Reviews (2002)

No. 14 Guidance Notes for Analysis and Evaluation of Chronic Toxicity and Carcinogenicity Studies (2002).

No. 15 Persistent, Bioaccumulative and Toxic Pesticides in OECD Member Countries, (2002)

No. 16 OECD Guidance for Industry Data Submissions for Pheromones and Other Semiochemicals and their Active Substances (Dossier Guidance for Pheromones and other Semiochemicals) (2003)

No. 17 OECD Guidance for Country Data Review Reports for Pheromones and Other Semiochemicals and their Active Substances (Monograph Guidance for Pheromones and other Semiochemicals) (2003)

No. 18 Guidance for Registration Requirements for Microbial Pesticides (2003)

No. 19 Registration and Work sharing, Report of the OECD/FAO Zoning Project (2003)

No. 20 OECD Workshop on Electronic Tools for data submission, evaluation and exchange for the Regulation of new and existing industrial chemicals, agricultural pesticides and biocides (2003)

No. 21 Guidance for Regulation of Invertebrates as Biological Control Agents (IBCAs) (2004)

No. 22 OECD Guidance for Country Data Review Reports on Microbial Pest Control Products and their Microbial Pest Control Agents (Monograph Guidance for Microbials) (2004)

No. 23 OECD Guidance for Industry Data Submissions for Microbial Pest Control Product and their Microbial Pest Control Agents (Dossier Guidance for Microbials) (2004)

No. 24 Report of the OECD Pesticide Risk Reduction Steering Group Seminar on Compliance (2004) 
No. 25 The Assessment of Persistency and Bioaccumulation in the Pesticide Registration Frameworks within the OECD Region (2005)

No. 26 Report of the OECD Pesticide Risk Reduction Group Seminar on Minor Uses and Pesticide Risk Reduction (2005)

No. 27 Summary Report of the OECD Project on Pesticide Terrestrial Risk Indicators (TERI) (2005)

No. 28 Report of the OECD Pesticide Risk Reduction Steering Group Seminar on Pesticide Risk Reduction through Good Container Management (2005)

No. 29 Report of the OECD Pesticide Risk Reduction Steering Group Seminar on Risk Reduction through Good Pesticide Labelling (2006)

No. 30 Report of the OECD Pesticide Risk Reduction Steering Group: The Second Risk Reduction Survey (2006)

No. 31 Guidance Document on the Definition of Residue [also published in the series on Testing and Assessment, No. 63] (2006, revised 2009)

No. 32 Guidance Document on Overview of Residue Chemistry Studies [also published in the series on Testing and Assessment, No. 64] (2006, revised 2009)

No. 33 Overview of Country and Regional Review Procedures for Agricultural Pesticides and Relevant Documents (2006)

No. 34 Frequently Asked Questions about Work Sharing on Pesticide Registration Reviews (2007)

No. 35 Report of the OECD Pesticide Risk Reduction Steering Group Seminar on "Pesticide Risk Reduction through Better Application Technology" (2007)

No. 36 Analysis and Assessment of Current Protocols to Develop Harmonised Test Methods and Relevant Performance Standards for the Efficacy Testing of Treated Articles/Treated Materials (2007)

No. 37 Report on the OECD Pesticide Risk Reduction Steering Group Workshop "Pesticide User Compliance' (2007)

No. 38 Survey of the Pesticide Risk Reduction Steering Group on Minor Uses of Pesticides (2007)

No. 39 Guidance Document on Pesticide Residue Analytical Methods [also published in the series on Testing and Assessment, No. 72] (2007)

No. 40 Report of the Joint OECD Pesticide Risk Reduction Steering Group EC-HAIR Seminar on Harmonised Environmental Indicators for Pesticide Risk (2007)

No. 41 The Business Case for the Joint Evaluation of Dossiers (Data Submissions) using Work-sharing Arrangements (2008)

No. 42 Report of the OECD Pesticide Risk Reduction Steering Group Seminar on Risk Reduction through Better Worker Safety and Training (2008)

No. 43 Working Document on the Evaluation of Microbials for Pest Control (2008)

... Guidance Document on Magnitude of Pesticide Residues in Processed Commodities - only published in the Series on Testing and Assessment, No. 96 (2008)

No. 44 Report of Workshop on the Regulation of BioPesticides: Registration and Communication Issues (2009)

No. 45 Report of the Seminar on Pesticide Risk Reduction through Education / Training the Trainers (2009) 
No. 46 Report of the Seminar on Pesticide Risk Reduction through Spray Drift Reduction Strategies as part of National Risk Management (2009)

No. 47 OECD Survey on Countries' Approaches to the Collection and Use of Agricultural Pesticide Sales and Usage Data: Survey Results (2009)

No. 48 OECD Strategic Approach in Pesticide Risk Reduction (2009)

No. 49 OECD Guidance Document on Defining Minor Uses of Pesticides (2009)

No. 50 Report of the OECD Seminar on Pesticide Risk Reduction through Better National Risk Management Strategies for Aerial Application (2010)

No. 51 OECD Survey on Pesticide Maximum Residue Limit (MRL) Policies: Survey Results (2010)

No. 52 OECD Survey of Pollinator Testing, Research, Mitigation and Information Management: Survey Results (2010)

No. 53 Report of the $1^{\text {st }}$ OECD BioPesticides Steering Group Seminar on Identity and Characterisation of Micro-organisms (2010)

No. 54 OECD Survey on Education, Training and Certification of Agricultural Pesticide Users, Trainers and Advisors, and Other Pesticide Communicators: Survey Results (2010)

No. 55 OECD Survey on How Pesticide Ingredients Other than the Stated Pesticide Active Ingredient(s) are Reviewed and Regulated: Survey Results (2010)

No. 56 OECD MRL Calculator User Guide (2011)

No. 57 OECD MRL Calculator MRL Statistical White Paper (2011)

No. 58 Report of the OECD Seminar on Pesticide Risk Reduction Strategies Near/in Residential Areas (2011)

No. 59 Report of the OECD Seminar on Risk Reduction through Prevention, Detection and Control of the Illegal International Trade in Agricultural Pesticides (2011)

No. 60 Guidance Document on the Planning and Implementation of Joint Reviews of Pesticides (2011)

No. 61 OECD Survey on Efficacy a Crop Safety Data Requirements \& Guidelines for the Registration of Pesticide Minor Uses: Survey Results (2011)

No. 62 OECD Survey on Regulatory Incentives for the Registration of Pesticide Minor Uses: Survey Results (2011)

No. 63 Guidance Document on Regulatory Incentives for the Registration of Pesticide Minor Uses (2011)

... Guidance Notes on Dermal Absorption - only published in the Series on Testing and Assessment, No. 156 (2011)

No. 64 Report of the Second OECD BioPesticides Steering Group Seminar on the Fate in the Environment of Microbial Control Agents and their Effects on Non-Target Organisms (2011)

No. 65 OECD Issue Paper on Microbial Contaminant Limits for Microbial Pest Control Products (2011)

No. 66 Guidance Document on Crop Field Trials [also published in the Series on Testing and Assessment, No. 164] (2011)

No. 67 OECD Guidance to the Environmental Safety Evaluation of Microbial Biocontrol Agents (2012)

No. 68 Report of the OECD Workshop on the Development of Harmonized International Guidance for Pesticide Terrestrial Field Dissipation Studies and Crosswalk of North American \& European Eco-Regions (2012) 
No. 69 OECD Survey on Integrity of Pesticides at the Manufacturing, Import and Distribution Stages: Survey Results (2012)

No. 70 Report of the OECD Workshop on Integrated Pest Management (IPM) Strategies for the adoption and implementation of IPM in Agriculture Contributing to the sustainable use of Pesticides and to Pesticide Risk Reduction (2012)

\section{Published separately}

OECD Guidance for Country Data Review Reports on Plant Protection Products and their Active Substances-Monograph Guidance (1998, revised 2001, 2005, 2006)

OECD Guidance for Industry Data Submissions on Plant Protection Products and their Active Substances-Dossier Guidance (1998, revised 2001, 2005)

Report of the Pesticide Aquatic Risk Indicators Expert Group (2000)

Report of the OECD Workshop on the Economics of Pesticide Risk Reduction (2001)

Report of the OECD-FAO-UNEP Workshop on Obsolete Pesticides (2000)

Report of the OECD Pesticide Aquatic Risk Indicators Expert Group (2000)

Report of the 2nd OECD Workshop on Pesticide Risk Indicators (1999)

Guidelines for the Collection of Pesticide Usage Statistics Within Agriculture and Horticulture (1999)

Report of the [1st] OECD Workshop on Pesticide Risk Indicators (1997)

Report of the OECD/FAO Workshop on Pesticide Risk Reduction (1995)

\section{(C) OECD 2012}

Applications for permission to reproduce or translate all or part of this material should be made to: Head of Publications Service, RIGHTS@oecd.org, OECD, 2 rue André-Pascal, 75775 Paris Cedex 16, France 


\section{ABOUT THE OECD}

The Organisation for Economic Co-operation and Development (OECD) is an intergovernmental organisation in which representatives of 34 industrialised countries in North and South America, Europe and the Asia and Pacific region, as well as the European Commission, meet to co-ordinate and harmonise policies, discuss issues of mutual concern, and work together to respond to international problems. Most of the OECD's work is carried out by more than 200 specialised committees and working groups composed of member country delegates. Observers from several countries with special status at the OECD, and from interested international organisations, attend many of the OECD's workshops and other meetings. Committees and working groups are served by the OECD Secretariat, located in Paris, France, which is organised into directorates and divisions.

The Environment, Health and Safety Division publishes free-of-charge documents in eleven different series: Testing and Assessment; Good Laboratory Practice and Compliance Monitoring; Pesticides; Biocides; Risk Management; Harmonisation of Regulatory Oversight in Biotechnology; Safety of Novel Foods and Feeds; Chemical Accidents; Pollutant Release and Transfer Registers; Emission Scenario Documents; and Safety of Manufactured Nanomaterials. More information about the Environment, Health and Safety Programme and EHS publications is available on the OECD's World Wide Web site (www.oecd.org/ chemicalsafety/).

This publication was developed in the IOMC context. The contents do not necessarily reflect the views or stated policies of individual IOMC Participating Organizations

The Inter-Organisation Programme for the Sound Management of Chemicals (IOMC) was established in 1995 following recommendations made by the 1992 UN Conference on Environment and Development to strengthen co-operation and increase international co-ordination in the field of chemical safety. The Participating Organisations are FAO, ILO, UNDP, UNEP, UNIDO, UNITAR, WHO, World Bank and OECD. The purpose of the IOMC is to promote co-ordination of the policies and activities pursued by the Participating Organisations, jointly or separately, to achieve the sound management of chemicals in relation to human health and the environment. 
This publication is available electronically, at no charge.

For this and many other Environment, Health and Safety publications, consult the OECD's World Wide Web site (www.oecd.org/chemicalsafety/)

or contact:

OECD Environment Directorate, Environment, Health and Safety Division

2 rue André-Pascal

75775 Paris Cedex 16

France

Fax: (33-1) 44306180

E-mail: ehscont@oecd.org 


\section{Foreword}

This OECD Guidance on Pesticide Compliance and Enforcement Best Practices was prepared by the OECD Expert Group on Pesticide Best Practices Compliance, as part of the risk reduction activities of the OECD Pesticide Programme.

The objective of this document is to provide guidance for promoting and monitoring compliance, in particular for pesticide regulators, including those that may not have their own compliance requirements, guidance or policies.

This document addresses the following areas of the pesticide lifecycle:

- Manufacturing and product integrity (active ingredients and enduse products);

- Distribution (including transportation and sale);

- Product use;

- Product storage; and

- Container recycling and disposal.

This document includes:

- Information, methods and techniques to facilitate compliance activities and/or programs; and

- Guidance and best practices on how risk management principles may be applied.

The overall structure of this document is summarised in the flow diagram shown on Figure 0.1 of the introduction.

This Guidance was approved out-of-session by the Working Group on Pesticides by written procedure that was finished on 20 February 2012. 
This document is being published under the responsibility of the Joint Meeting of the Chemicals Committee and the Working Party on Chemicals, Pesticides and Biotechnology, which has agreed that it be unclassified and made available to the public. 


\section{Table of contents}

Preface

Introduction

Chapter 1. Regulatory Requirements and Compliance and Enforcement Activities.

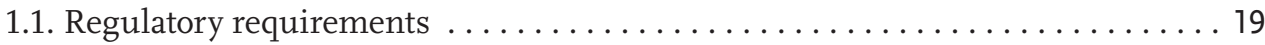

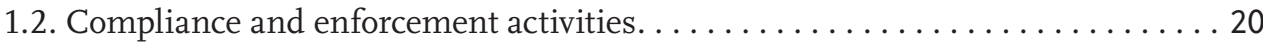

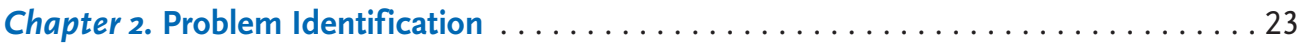

2.1. Types of problems and possible root causes $\ldots \ldots \ldots \ldots \ldots \ldots \ldots \ldots \ldots$

2.2. Compliance Monitoring and Verification $\ldots \ldots \ldots \ldots \ldots \ldots \ldots \ldots \ldots \ldots \ldots \ldots \ldots \ldots$

Chapter 3. Evaluating Risks of Known or Suspected Non-Compliance . . . . . . . . . . 27

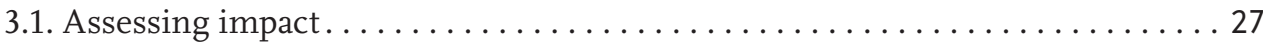

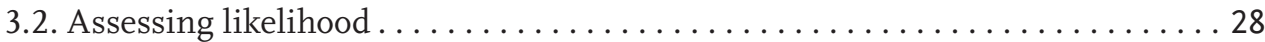

3.3. Uncertainty and assessing unknowns. . . . . . . . . . . . . . 29

3.4. Level of evidence and reliability of information $\ldots \ldots \ldots \ldots \ldots \ldots \ldots \ldots$

3.5. Integrating risk assessment information $\ldots \ldots \ldots \ldots \ldots \ldots \ldots \ldots \ldots \ldots \ldots$

Chapter 4. Risk Management Decision Making and Implementing Compliance and

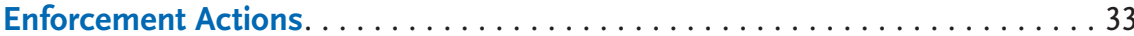

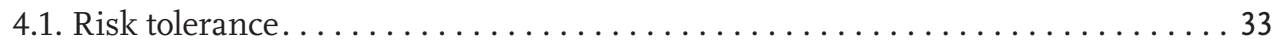

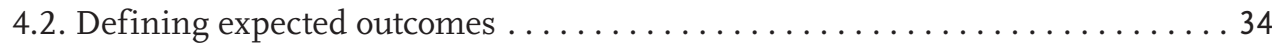

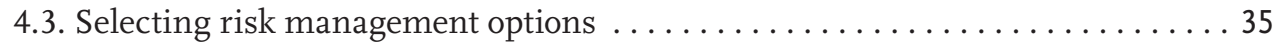

4.4. Communicating compliance and enforcement actions $\ldots \ldots \ldots \ldots \ldots$

Chapter 5 . Evaluation of Effectiveness $\ldots \ldots \ldots \ldots \ldots \ldots \ldots \ldots \ldots \ldots \ldots \ldots$ 


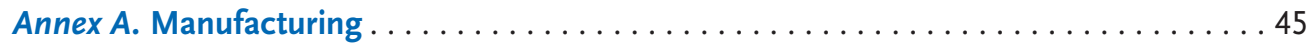

A.1. Regulatory requirements and compliance and enforcement activities. . . . . 45

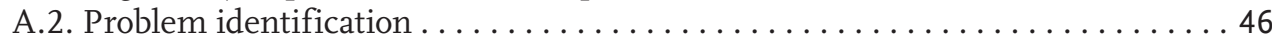

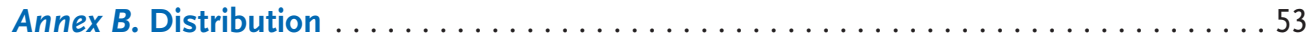

B.1. Regulatory requirements and compliance and enforcement activities. . . . . 53

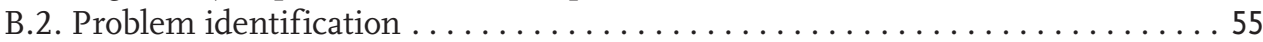

Annex C. Storage . . . . . . . . . . . . . . . . . . . . . . . . . . 59

C.1. Regulatory requirements and compliance and enforcement activities. . . . . 59

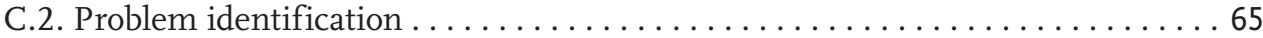

Annex D. Use................................... 69

D.1. Regulatory requirements and compliance and enforcement activities. . . . . 69

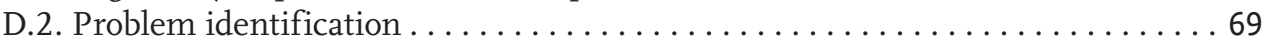

Annex E. Container Recycling and Disposal. . . . . . . . . . . . . . . . 73

E.1. Regulatory requirements and compliance and enforcement activities . . . . 73

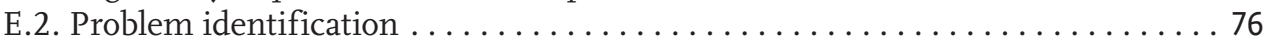

Appendix I. Core Principles of Compliance and Enforcement. . . . . . . . . . . . . 79

Appendix II. Glossary ........................................ 81

Figures

Figure 0.1 . Flow Diagram Summary $\ldots \ldots \ldots \ldots \ldots \ldots \ldots \ldots \ldots \ldots \ldots \ldots$

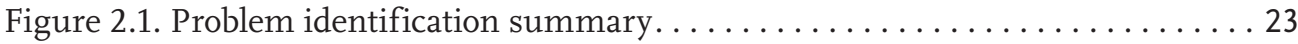

Table

Table 1.1. Compliance and enforcement activities ................... 20 


\section{Preface}

In 2003, the OECD Pesticide Risk Reduction Steering Group (RRSG) held its first Seminar and chose the topic of compliance because of its importance to risk reduction and to the proper functioning of pesticide regulatory systems (OECD, 2004). In 2006, Canada hosted an OECD Workshop focusing on Pesticide User Compliance issues. A survey was conducted prior to the workshop to collect information on what regulators do to promote compliance and how users perceive compliance mechanisms (OECD, 2007). Following these two events, the RRSG discussed how to implement the recommendations developed from the 2006 Workshop, as well as the outcomes of the second OECD Risk Reduction Survey (OECD, 2006).

At its November 2007 meeting, the RRSG requested that an Expert Group on Compliance be created to begin discussions on the development of a Compliance Best Practice Guidance document whose targeted audience would primarily be pesticide regulators. In addition, the International Code of Conduct on the Distribution and Use of Pesticides (FAO, 2002) was identified as an important basis for the creation of this OECD Guidance document.

The Expert Group first met by teleconference in April 2008 and developed a project workplan. Between 2009 and 2011, a number of meetings (i.e. teleconferences) were held to advance the drafting of this Guidance. All countries on the Expert Group were in charge of preparing specific Chapters and Annexes and are gratefully thanked here for their efforts and active participation in this project. In addition, the RRSG continuously oversaw the process of guidance development during its annual meetings in 2008-2011. 


\section{References for the Preface}

FAO (Food and Agriculture Organization of the United Nations) (2002), International Code of Conduct on the Distribution and Use of Pesticides, www. fao.org/docrep/005/Y4544E/Y4544eoo.htm.

OECD (2004), Series on Pesticides No.24, Environment, Health and Safety: ENV/JM/MONO(2004)6 - Report of the OECD Pesticide Risk Reduction Steering Group Seminar on Compliance, www.oecd.org/officialdocuments/ displaydocumentpdf $/$ ? cote $=E N V / J M / M O N O(2004) 6$ ddoclanguage $=e n$.

OECD (2007), Series on Pesticides No.37, Environment, Health and Safety: ENV/ JM/MONO(2007) 9 - Report on the OECD Pesticide Risk Reduction Steering Group Workshop "Pesticide User Compliance", www.oecd.org/officialdocuments/ displaydocumentpdf/?cote $=E N V / J M / M O N O(2007) 9$ Qddoclanguage $=e n$.

OECD (2006), Series on Pesticides No.30, Environment, Health and Safety: ENV/ JM/MONO(2006) 14 - Report of the OECD Pesticide Risk Reduction Steering Group: The Second Risk Reduction Survey, www.oecd.org/officialdocuments/ displaydocumentpdf $/$ ? cote $=E N V / J M / M O N O(2006) 14$ Qdoclanguage $=e n$. 


\section{Introduction}

This document provides general guidance for pesticide regulators, including those that may not have their own compliance requirements, guidance or policies. It is not intended to supersede or substitute any national/regional requirements, guidance or policies on this subject as administered by specific regulatory authorities. Regulated parties ${ }^{1}$ must continue to follow their country-specific requirements. The document is focussed primarily on considering health and environmental risks.

The objective of this document is to provide guidance for promoting and monitoring compliance in the following areas of the pesticide lifecycle:

- Manufacturing and product integrity (active ingredients and enduse products);

- Distribution (including transportation and sale);

- Product use;

- Product storage; and

- Container recycling and disposal.

This document includes:

- Information, methods and techniques to facilitate compliance activities and/or programs; and

- Guidance and best practices on how risk management principles may be applied.

In preparing this document, the International Code of Conduct on the Distribution and Use of Pesticides: Guidelines on Compliance and Enforcement of a Pesticide Regulatory Programme (FAO, 2006) was considered. In particular, the core principles of the Code were applied (see Appendix I: Core Principles of Compliance and Enforcement). 
Figure 0.1. Flow Diagram Summary

\section{Overview of the OeCD Pesticide Compliance \& Enforcement Best Practice Guidance}

\section{Regulatory Requirements and Compliance AND ENFORCEMENT ACTIVITIES}

Regulated parties must comply with established requirements to minimise risks to human health and the environment. Chapter 1 provides an overview of these requirements, as well as the compliance and enforcement activities that regulators can conduct to ensure compliance. Detailed guidance is available in the Annexes.

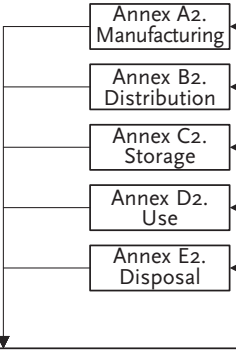

\section{Risk Evaluation of Non-Compliance}

Chapter 3 provides factors to be considered in assessing the impact and likelihood of a noncompliant event. It also provides guidance on integrating the assessment of uncertainties and reliability of information into the risk evaluation.

\section{Risk Management: Decision Making}

An important initial step following risk evaluation is to determine whether the risk is tolerable or if it requires further action. If action is required, the expected outcomes should be defined. Chapter 4 contains factors that should be considered in selecting a course of action. The risk management options include those outlined in legislation or regulations.

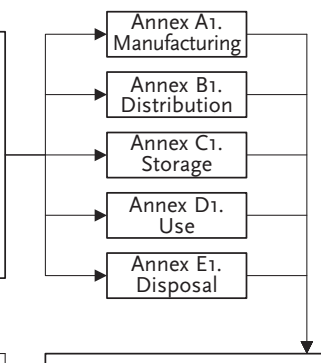

\section{Problem IDEntification}

Throughout the pesticide life-cycle, problems or issues posing potential risks may arise due to a range of root causes. Chapter 2 includes guidance and selected methods to detect problems, monitor compliance and determine whether a problem of non-compliance exists. Detailed guidance is available in the Annexes. 
Definitions of compliance-related terms are available in Appendix II: Glossary.

The structure of this document is summarised in the flow diagram in Figure 0.1.

\section{Note for the Introduction}

1 Including but not limited to manufacturers; importers, distributors (vendors, retailers and wholesalers); users; container recyclers.

\section{Reference for the Introduction}

FAO (2006), International Code of Conduct on the Distribution and Use of Pesticides: Guidelines on Compliance and Enforcement of a Pesticide Regulatory Programme, www.fao.org/WAICENT/FAOINFO/AGRICULT/AGP/AGPP/Pesticid/Code/ Download/Compliance06.pdf. 



\section{Chapter 1}

\section{Regulatory Requirements and Compliance and Enforcement Activities}

\subsection{Regulatory requirements}

Throughout the pesticide life-cycle, regulated parties must comply with established requirements to minimise risks to human health and the environment. These requirements may be regulated under multiple pieces of legislation by more than one authority/department, including different levels of government (e.g. federal, state/provincial, and municipal). Outlined in the following Annexes ${ }^{1}$ are specific principles and requirements to minimise risks for each stage of the pesticide life-cycle:

- Annex A 1. Manufacturing

- Annex B 1. Distribution

- Annex C 1. Storage

- Annex D 1. Use

- Annex E 1. Container Recycling and Disposal

Note: Regulatory requirements related to the evaluation and approval of pesticide products will not be discussed in this document. This information can be found in other pesticide-related national, regional, and OECD documents. 


\subsection{Compliance and enforcement activities}

Regulators conduct compliance and enforcement activities to ensure regulated parties comply with all applicable regulatory requirements. These activities can be divided into three main types of activities: compliance promotion, compliance monitoring and responding to potential situations of non-compliance (Table 1.1).

Table 1.1. Compliance and enforcement activities

\begin{tabular}{|c|c|c|c|}
\hline $\begin{array}{l}\text { COMPLIANCE AND } \\
\text { ENFORCEMENT ACTIVITY }\end{array}$ & COMPLIANCE PROMOTION & COMPLIANCE MONITORING & $\begin{array}{l}\text { RESPONDING TO } \\
\text { NON-COMPLIANCE }\end{array}$ \\
\hline Intent & $\begin{array}{l}\text { Improve regulated parties' } \\
\text { awareness of regulatory } \\
\text { requirements }\end{array}$ & $\begin{array}{l}\text { Verify that regulatory } \\
\text { requirements are being } \\
\text { met }\end{array}$ & $\begin{array}{l}\text { Bring a known or potential } \\
\text { non-compliance situation } \\
\text { into compliance }\end{array}$ \\
\hline Examples & $\begin{array}{l}\text { - Risk communication } \\
\text { - Information bulletins } \\
\text { - Reports } \\
\text { - Seminars } \\
\text { - Trade shows } \\
\text { - Website } \\
\text { - Stakeholder engagement } \\
\text { and partnerships }\end{array}$ & $\begin{array}{l}\text { - Inspections } \\
\text { - Market surveys } \\
\text { - Sampling }\end{array}$ & $\begin{array}{l}\text { - Letters } \\
\text { - Meetings } \\
\text { - Orders } \\
\text { - Recalls } \\
\text { - Administrative } \\
\text { penalties } \\
\text { - Prosecutions }\end{array}$ \\
\hline
\end{tabular}

\section{Compliance promotion}

Compliance promotion includes a number activities aimed at improving awareness of regulatory requirements. Promoting compliance through raising awareness and undertaking educational and outreach activities is an effective mechanism to enable compliance, particularly for emerging compliance issues, new regulatory requirements/decisions and/or policies. Regulators should promote and support open and transparent activities that encourage Regulators, industry, consumers and other stakeholders to discuss compliance and enforcement requirements and challenges associated with maintaining compliance. Providing information to users (e.g. proper pesticide use, information on compliance and enforcement decisions, etc.) can enable them to make appropriate and informed choices related to pesticide products and minimise health risks. 


\section{Compliance monitoring}

Compliance monitoring refers to monitoring the activities of regulated parties to ensure they are following established policies and procedures and are complying with all appropriate regulations that apply to them. Monitoring activities can vary and include inspections, market surveys and product-sampling programs.

\section{Responding to known or potential situations of non-compliance}

When the regulator is notified or becomes aware that a regulated party is potentially not following appropriate laws and regulations, it should verify the information and work with the regulated party to bring the product or activity into compliance with the regulatory requirements. Potential issues may be identified by consumers, industry, provincial, territorial or federal regulatory agencies, international partners or through the regulator's own monitoring activities.

The structure of this best practice guidance is aligned with responding to known or potential situations of non-compliance. In addition, compliance promotion and compliance monitoring best practices are highlighted throughout.

\section{Note for Chapter 1}

1 Section numbers in the Annexes follow the same numbering scheme as the main document. The Annexes are intended to be subsections of the main document. 



\section{Chapter 2}

\section{Problem Identification}

Throughout the pesticide life-cycle, a range of problems or issues posing potential risks may arise. The steps to detect, identify and classify these problems/issues are summarised in Figure 2.1.

\section{Figure 2.1. Problem identification summary}

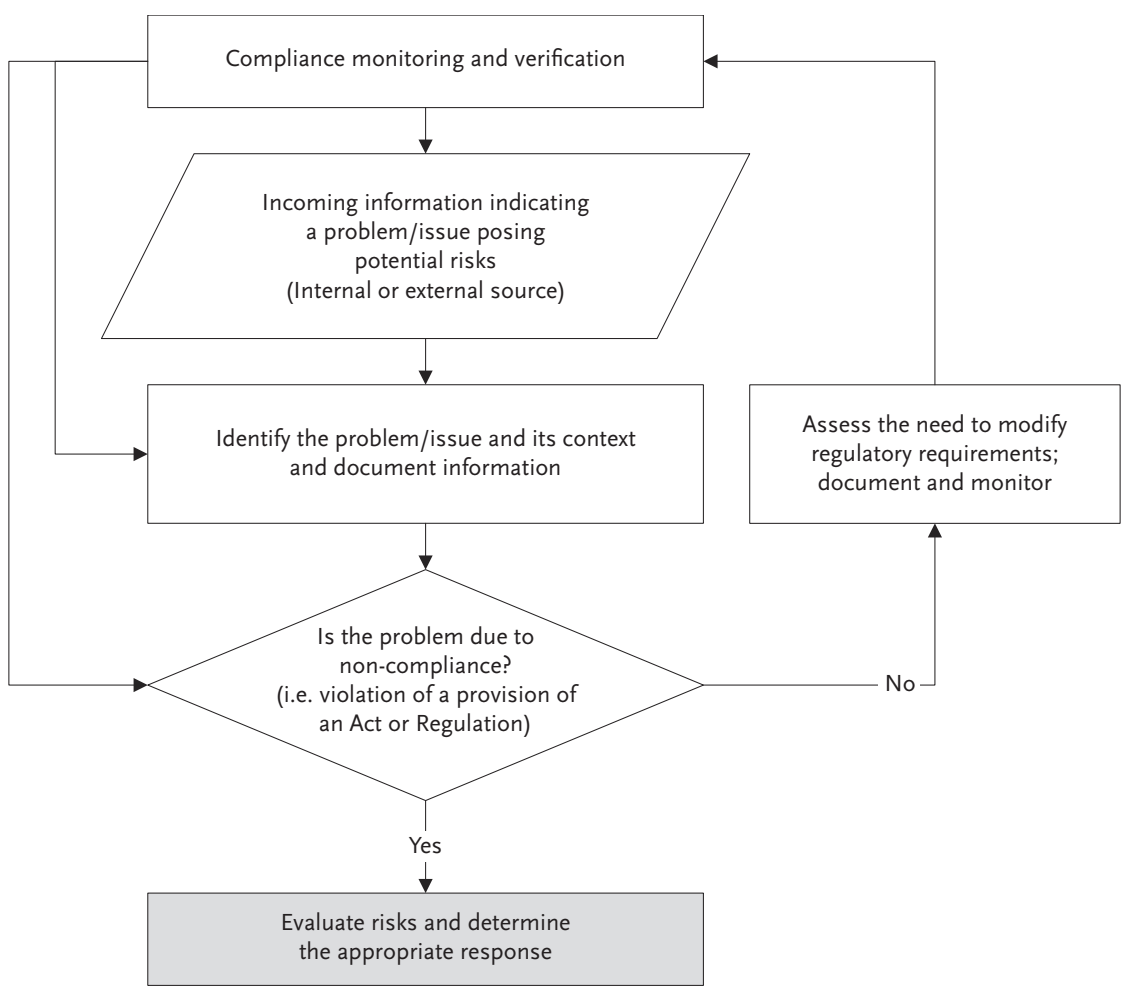


The methods of detecting problems will vary by regulatory authority and may be outlined in legislative or regulatory documents. Analyzing the following types of information sources has been found to be an effective method to detect the existence of problems:

- Information gathered from on-site inspections;

- Information gathered from risk awareness surveys;

- Incident and/or adverse effects report(s) or consumer complaints (e.g. adverse health effects, reported inefficacy, crop damage, etc.);

- Information from other regulatory officials, including customs or other law-enforcement officials, foreign authorities, etc. (e.g. information about the production, export or import of unregistered or counterfeit pesticides, information about the delivery of pesticides to unknown distributors);

- Previous incidents of non-compliance by the regulated party;

- Information on changes to purchase patterns for ingredients, specifically active ingredients/substances;

- Reports of a change in physical characteristics of the product (e.g. color, viscosity, texture of product) by the end user;

- Laboratory analysis of product samples taken at the retail or user level for guarantee, formulants and presence of microcontaminants, or detecting counterfeit pesticides;

- Analyses of food (fruits/vegetables) or plants show the presence of active ingredients/substances that are not allowed for use in the producing country;

- Sales records;

- Labelling/packaging of pesticides (e.g. suspicious batch numbers or production dates);

- Delivery receipts or bills indicating illegal actions (e.g. several distributors and transporters);

- Staff observations at a storage facility;

- Residue-monitoring programs indicate residues above maximum residue limits (MRLs) stated for the substance/commodity or for substance/commodity combinations having no MRLs; 
- Feedback from producer groups, consumer organisations and manufacturers on the lack of information or clarity on labels leading to incorrect use of the product; and

- Neighbour complaints of container dumps.

The capacity of the regulator and the priorities of the regulatory program will influence how and what information is analyzed.

\subsection{Types of problems and possible root causes}

An important initial step is to clearly identify the problem or issue and its context and document as much information as possible. The types or classes of problems/issues, as well as their possible root causes are listed for each stage of the pesticide life-cycle in the following Annexes:

- Annex A 2.1 Manufacturing

- Annex B 2.1 Distribution

- Annex C 2.1 Storage

- Annex D 2.1 Use

- Annex E 2.1 Container Recycling and Disposal

\subsection{Compliance Monitoring and Verification}

Once it has been determined that a problem is likely to exist, it must be determined whether the problem is due to non-compliance and/or due to some other type of problem. In deciding whether a problem of noncompliance exists, one should consider the following:

- Is the source of the information objective/reliable?

- Is the information sufficient to suggest non-compliance?

- Are there related circumstances or information indicating that a problem does exist?

- Is there a history of previous non-compliance?

A number of monitoring mechanisms and methods can be used at each stage of the pesticide life-cycle to effectively assess compliance with established regulatory requirements; best practices are listed in the following Annexes: 
- Annex A 2.2 Manufacturing

- Annex B 2.2 Distribution

- Annex C 2.2 Storage

- Annex D 2.2 Use

- Annex E 2.2 Container Recycling and Disposal

If it is determined that a problem is due to non-compliance with regulatory requirements, the regulator should proceed to evaluate the risks of the situation to determine the appropriate response. If it is determined that the problem is not related to non-compliance with regulatory requirements, it may be appropriate to assess the need to modify regulatory requirements. 


\section{Chapter 3}

\section{Evaluating Risks of Known or Suspected Non-Compliance}

The degree of risk to human health, the environment and regulatory integrity ${ }^{1}$ (respect for rule of law) represented by an incident or event should be assessed by multiplying the impact (i.e. the seriousness of the consequences) by the likelihood (i.e. the probability of the consequences occurring).

$$
\text { Risk }=\text { Impact } \times \text { Likelihood }
$$

Judging the significance of the risks in order to determine the appropriate enforcement response may include input from health and environmental-assessment experts. Experts should be consulted, particularly when it helps to reduce uncertainties.

\subsection{Assessing impact}

To assess impact, regulators must define a process to facilitate the consideration of the:

- Potential impact on humans (e.g. workers, bystanders), particularly vulnerable populations (e.g. children);

- Potential impact on the environment, particularly vulnerable or sensitive populations or habitats (e.g. species at risk);

- Potential impact on regulatory integrity;

- Level of product toxicity/exposure; and

- Amount of product/ingredients involved.

In addition, there may be additional risk factors to consider at the following stages of the pesticide life-cycle: 
- Manufacturing:

- formation of micro-contaminants and impurities of concern

- use pattern of modified pesticides

- Distribution:

- specific risks due to handling of packaged pesticides such as leaking/broken packages, incorrect labelling with regard to hazards, escape of gases in closed containers due to lack of ventilation or permeable pesticide packages, product damage due to inappropriate transportation conditions (high/low temperature, rough handling)

- Container Recycling and Disposal:

- who or what might be exposed to improperly disposed of containers or pesticide residues on plastic that is recycled for inappropriate uses

\subsection{Assessing likelihood}

To assess likelihood, regulators must define a process to facilitate the consideration of the:

- Level of demand for the product;

- Presence of the product in the marketplace;

- Opportunities for risk mitigation by the user (e.g. literacy and knowledge of the user);

- Extent of any misleading/falsification of information by the manufacturer, distributor, pesticide user or container recycler, etc.; and/or

- Size of the impacted community.

An analysis of the likelihood that the impact will grow/increase over time is also a consideration that may be influenced by several factors including, but not limited to, the following:

- Presence/perceived presence of economic or other incentives/ enablers (e.g. a competitive marketplace);

- Regulated party's perception of the likelihood of getting caught; 
- Regulated party's perception of the benefits to them vs. the costs of non-compliance (financial or other benefits vs. consequences of enforcement action);

- Regulated party's perception of the health and environmental risks;

- Observed/assumed attitudes or behaviours;

- Level of knowledge/understanding of regulatory requirements; and/or

- Extent or size of the problem.

\subsection{Uncertainty and assessing unknowns}

A method of recognising uncertainties or unknowns should be incorporated in the compliance risk assessment process (problem identification and risk evaluation), including how the assessment should be documented and what kind of report is required. The transparency of the assessment report and the accessibility of it to parties outside a regulatory organisation must be considered.

Uncertainties and unknowns must be considered with regard to the potential impacts that could occur if they were found to be true, and the likelihood of that impact occurring given the circumstances. A thorough examination of the circumstances is required, including such things as:

- Existing restrictions/requirements;

- Labelling safeguards that may mitigate the non-compliance that has occurred;

- Propensity for restrictions/labelling to be followed;

- User knowledge of the product's limitations/risks;

- Gap filled by the product (benefit);

- Liability of the regulator;

- Reversibility of a health or environmental impact; and

- Potential to invoke additional non-compliance.

In cases where there is potential for irreversible, serious and/or widespread harm to human health or the environment, immediate action may be appropriate to prevent serious harm from occurring. In these 
cases, the level of supporting evidence of a risk need not be as strong as that of less hazardous situations. As an example, if a person died from a product potentially due to a product-integrity or labelling concern, the level of evidence needed to take an immediate precautionary action (e.g. halt production, halt distribution/sale, etc.) would be reduced given the high health or environmental impact.

In other cases where the potential adverse impacts are lower, regulators should consider both the severity and probability of the noncompliance when deciding on compliance and enforcement actions. Historical evidence, public surveys and other relevant information can be used to support the decision(s) made.

\subsection{Level of evidence and reliability of information}

Assessments provided outside of a regulatory authority should be evaluated by the regulator. The following should be considered when evaluating these assessments:

- Assessor's agenda and interests;

- Reliability of past information received;

- Ability to reproduce findings;

- Expertise/credentials;

- Compliance history; and

- Other regulatory oversight(s) impacting the assessment.

Regulators should never base decisions on mere speculation. Whenever a decision is made that negatively impacts a stakeholder, the decision is likely to be challenged to some extent, based on facts or law. The amount of evidence used to support the regulator's compliance decision should be proportionate to the impact of the decision. The regulator must consider the expected level of understanding of the regulated party and whether there is any room for interpretation/ confusion as a result of poor communication on the part of the regulator.

\subsection{Integrating risk assessment information}

Regulators should define a process to consider assessments made by the following groups and integrate them into a single assessment: 
- Regulator's internal risk assessors;

- Other regulators (e.g. pesticide regulators in other countries);

- Private sector, industry, etc. (i.e. those with a commercial interest);

- Consumers and users;

- Not-for-profit interest groups;

- General public;

- Elected officials; and

- Advisory boards.

Clearly, each of these groups could have opinions and vested interests in the outcome of a compliance decision. It is important from a perspective of building public confidence and a culture of compliance that all of these groups be given an equal opportunity to provide input. Any assessments put forth must be based on as much factual evidence as possible. Where uncertainties remain, the information must be considered in its totality with the potential for risks to occur, weighed against the potential net benefits gained. This will be a value judgement and must focus on health and environmental safety. If these risks are limited, risks to regulatory integrity should be considered. For example, the regulator may consider the risk of a perceived atmosphere/culture of non-compliance in the regulated community and the potential for more significant non-compliance that may result in health and safety risks.

\section{Notes for Chapter 3}

1 Regulatory integrity risks are risks that are generally associated with business risks (e.g. legal liability, program integrity, regulated parties' respect for rule of law, public and stakeholder confidence) and are not directly related to health or environmental risks. However, if not addressed, regulatory integrity risks may result in eventual health and/or environmental risks due to further non-compliance by a company and/ or the regulated community. 
2 Example (Canada): A competitor complaint led to the discovery of a company wilfully importing a lower-cost, unregistered active ingredient. The situation was assessed to have negligible health and environmental risks as the unregistered product was nearly identical to a registered product. However, the risk to regulatory integrity in this situation was assessed to be high due to the significant economic advantage (CAD 490 000) and source of the complaint (another regulated party). Therefore, appropriate actions were taken to deter further non-compliance by the company and its competitors and maintain the regulated community's confidence in the regulatory system. 


\section{Chapter 4}

\section{Risk Management Decision Making and Implementing Compliance and Enforcement Actions}

\subsection{Risk tolerance}

To ensure effective and efficient use of compliance resources rather than conducting "one-off" inspections to confirm compliance, it may be appropriate, where health and safety risks are minimal, to collect reported incidents or implement other targeted oversight activities until such time that enough data has been collected to warrant an enforcement action.

Once it has been determined that non-compliance has occurred and the actual risk(s) have been assessed (health and safety, the environment and/or regulatory integrity risks), it must be determined whether that risk is tolerable or if it must be managed (based on country-specific considerations). If this is the case, what strategy should be applied to reduce or eliminate the risk(s)?

The following factors may need to be considered in determining the level of risk tolerance:

- Political salience: What is the current interest/importance of the issue or sector affected? What is the expected short- and longerterm outlook of the level of interest/importance in the issue/ sector? What historical information, incidents or sensitivities need to be considered?

- Perceived risk: What is the perceived risk(s) of the public and other stakeholder(s), particularly vulnerable populations, and how do they compare to the actual assessed risks? 
- Acceptable risk: What is the level of risk that the user is willing to accept?

- Distribution of risks/benefits: Who is negatively and positively impacted by the risks and benefits?

A Risk Management Matrix combines risk evaluation (i.e. determination of impact and likelihood levels) and risk tolerance into an integrated decision matrix to guide decision making based on the overall level of risk. An example is provided below:

\begin{tabular}{|c|c|c|c|c|}
\hline \multirow{4}{*}{$\stackrel{\longleftarrow}{\longleftarrow}$} & $\begin{array}{c}\text { High } \\
\text { (serious) }\end{array}$ & $\begin{array}{c}\text { Measures needed } \\
\text { to mitigate risk. } \\
\text { Monitor. }\end{array}$ & $\begin{array}{l}\text { Immediate measures } \\
\text { needed to mitigate } \\
\text { risk. Monitor. }\end{array}$ & $\begin{array}{c}\text { Expedite } \\
\text { immediate measures } \\
\text { to mitigate risk. }\end{array}$ \\
\hline & $\begin{array}{l}\text { Medium } \\
\text { (moderate) }\end{array}$ & $\begin{array}{c}\text { Accept risk but } \\
\text { monitor. Some } \\
\text { measures may be } \\
\text { necessary. }\end{array}$ & $\begin{array}{c}\text { Measures needed } \\
\text { to mitigate risk. } \\
\text { Monitor. }\end{array}$ & $\begin{array}{l}\text { Immediate measures } \\
\text { needed to mitigate } \\
\text { risk. Monitor. }\end{array}$ \\
\hline & $\begin{array}{l}\text { Low } \\
\text { (slight) }\end{array}$ & Accept risk. & $\begin{array}{l}\text { Accept risk but } \\
\text { monitor. Some } \\
\text { measures may be } \\
\text { necessary. }\end{array}$ & $\begin{array}{c}\text { Measures needed } \\
\text { to mitigate risk. } \\
\text { Monitor. }\end{array}$ \\
\hline & & $\begin{array}{c}\text { Low } \\
\text { (Unlikely) }\end{array}$ & $\begin{array}{c}\text { Medium } \\
\text { (Likely) }\end{array}$ & $\begin{array}{c}\text { High } \\
\text { (Very Likely) }\end{array}$ \\
\hline
\end{tabular}

\subsection{Defining expected outcomes}

Regulators are accountable for upholding their mandate of protecting human health and the environment. They should have a clear understanding of where the greatest risks are present and where to target resources. They should be transparent and clearly identify the types of compliance activities that they will deliver.

Regulators should define expected outcomes (realistic, short- and long-term, compliance-specific) and link them to risk-reduction outcomes. Measurable and feasible indicators of success in achieving stated outcomes should be established. Outcomes must be realistic, and targets should be reasonable and provide adequate time to be reached, and actions taken should provide the least level of intrusiveness to reach the desired outcome. 
In specific situations, it is most important that the desired outcomes be clear so that the regulated party is informed of what is expected of them and by when, since failure to meet the expectations can make them subject to additional enforcement action. The regulated party should understand how the regulator will determine if they have complied.

\subsection{Selecting risk management options}

\subsubsection{Analysis}

When it has been determined that action is required, an appropriate type of action (e.g. facilitation, inspection, monitoring, measuring, investigation, enforcement) must be selected to effectively mitigate the risks. When more than one action or option may be appropriate, a stepwise approach is encouraged (i.e. regulators should use the most effective means of enforcement to achieve compliance while maintaining a fair, transparent and uniform approach).

The seriousness of the violation and the reasons for the non-compliance should be the primary considerations in making this decision. Mitigation plans should consider actions related to the product (e.g. detention, forfeiture, confiscation, sampling, disposition, re-labelling, recall, storage, shelf removal, halt production, etc.) and actions related to the contravener (e.g. education, warning, compliance order, fine, injunction, court order, prosecution) as afforded by the regulatory authority's legislation. As each situation of non-compliance is unique, ${ }^{1}$ categorising situations and reacting with the corresponding standardised enforcement response may not always be appropriate. Instead, a predictable decision-making process should be established that allows the actions to be tailored to the situation, while ensuring the response is fair and transparent.

In selecting a course of action, it is recommended that the following be considered:

- Is immediate action required to mitigate health, safety or environmental concerns?

- What was the cause of non-compliance (e.g. absence of knowledge; absence of will to comply [i.e. intent]; absence of capacity/ability to comply)?

- What is the contravener's compliance history? 
- Did the contravener have any control over the non-compliance (i.e. have they done their due diligence)? Does the contravener have the expertise to take the necessary action?

- Has the contravener demonstrated willingness and ability to achieve compliance? Is there evidence indicating that the contravener has already taken corrective action?

- Have certain types of action or strategies had a record of delivering successful results under similar circumstances?

- What actions or strategies were selected by other regulators in dealing with a similar problem under similar circumstances?

- Is the course of action cost-effective?

- How will the action impact the contravener?

- How might the action impact other regulators, including those in other countries?

- What is the level of public/political perception and sensitivities related to this issue?

- What, if any, related regional variability exists (e.g. demographic, cultural, geographical/environmental)?

When a course of action has been identified, the following should be defined:

- What is the underlying cause of non-compliance that is being addressed?

- Who is responsible for delivering the action (e.g. regulators, industry) and participating in the delivery of the action (e.g. other partners)?

- What is the legal liability of the regulator associated with any action or lack thereof?

- Are there potential negative consequences (e.g. long term economic harm, introduction of new health risks) associated with identified course of action?

- Is the action likely to deter future non-compliance (i.e. achieve and maintain continuing compliance)?

- Is the action likely to create a culture of compliance whereby other potential violators will choose to comply with the rules? 


\subsubsection{Options}

The root cause of non-compliance is a key factor to consider when determining whether promotion, risk communication, facilitation, or consultation is appropriate, or if inspection, monitoring, measuring or targeted enforcement programs need to be established. To best achieve and maintain compliance, more than one type of intervention may be appropriate for a particular infraction. The development of a targeted monitoring strategy helps to define the elements of the compliance and enforcement response. For instance, if non-compliance is detected, it may be decided to carry out a particular enforcement response with the regulated party, and to also carry out a compliance monitoring program to determine if this incident is unique or more widespread. Depending on the propensity for the violation to arise elsewhere, the regulator may want to put together a compliance promotion program to inform other regulated parties of their obligations.

Certain types of non-compliance can be corrected or prevented through compliance promotion programs, written correspondence or oneon-one meetings to address the infraction. The majority of contraveners will correct their behaviour if they are aware of the rules to follow. Compliance promotion would typically occur when the infraction is the result of a lack of knowledge of the rules to be followed or lack of an understanding of the rules. If the regulated party has no previous history or wilful intent to be non-compliant, then a variety of resolutions may be effective such as:

- Clarification of the Act/regulations/policies/conditions;

- Regulatory documents/standards provided; and

- Voluntary shut down until compliance restored (applicable to manufacturers).

Those that refuse should be dealt with swiftly in an escalated risk-based enforcement approach until compliance is restored. Countries that have the authority may deem it necessary to deny any of the regulated party's future applications/submissions for registration/permits/approvals until compliance is resolved. In the case of end users, they may be prosecuted under the legislation or have their licensing authorisation revoked, meaning they can no longer use pesticides. 
Adverse publicity is a very effective way to address non-compliance, often more so than any imposed actions or fines. It can be used to inform stakeholders that the contravener has been involved in an illegal activity and can result in changes in business agreements, loss of sales, potential lawsuits and further sanctions by other regulators, private and corporate entities.

An enforcement action can be taken against any person/company that committed a violation, including a manufacturer, registrant, distributor, retailer, user or person responsible for the product at the time of the infraction. The knowledge, will and ability of the person/company to comply and their role in creating the situation must be considered. Accountability for the product should be directed at the person/company who instigated the violation, but one must consider the reliability of evidence that they were involved. In addition, their ability to address the problem should be considered in risk management response.

Where the regulated party is willing to comply, regulators can negotiate formal commitments with establishments to undertake voluntary compliance measures as an alternative to legislated enforcement actions under a given Act. Where circumstances permit (e.g. outside the realm of establishing monetary penalties and court rulings), the contravener should be involved in determining corrective measures. They may have alternative solutions amenable to the regulator, which they may be more inclined to implement than an imposed measure. It also provides an opportunity for the regulated party to identify what support they need from regulators in developing and implementing product stewardship initiatives. Product recalls, although quite intrusive and costly for industry to employ, may be essential where the risks associated with a product are clearly identified and are deemed unacceptable.

International collaboration and action may be an appropriate and effective option in situations of illegal export and import, where one country could use assistance to correct a non-compliant situation originating from another country. For example, authorities from Country A could take enforcement action on distributors in their country who are knowingly exporting pesticides (not approved for use in Country B) directly to users in Country B.

One proactive approach in getting industry to be compliant would be to highlight incentive programs that promote good stewardship practices 
exhibited by regulated parties. This could include things such as ISO accreditation status, which could influence the sales/use of the company's services/products. It would also be beneficial if regulators encouraged industry and other relevant organisations to monitor pesticides on the market (e.g. through sample analysis) to ensure compliance with the registration. In addition, industry could develop procedures to prevent counterfeiting (e.g. use of special packages or the addition of marker substances). In the event that a pesticide, which is not in accordance with the registration, is found to be distributed, a registration holder should immediately inform regulators.

Clearly there is no "one size fits all" solution and regulators must use their experience and judgement when deciding upon an appropriate enforcement action, including the possibility of no immediate action. Regulators must also review and consider any internal policies when making their decisions.

\subsection{Communicating compliance and enforcement actions}

\subsubsection{Communicating with the contravener}

Any correspondence or records of agreements should be documented and linked with the contravener's file for future reference. Ensuring that the contravener's senior management is made aware of the necessity to comply can be an effective method of achieving compliance without having to escalate the enforcement action taken.

Any enforcement action should outline the actions to be taken and the deadlines to establish compliance or to respond with a plan for corrective action with self-imposed deadlines.

\subsubsection{Communicating with the public}

Publicly reporting contraveners on the regulator's website can be an effective compliance action. Benefits include:

- Improved public confidence in pesticide regulation through increased transparency and public awareness of the regulatory authority's compliance and enforcement programs and activities; 
- Improved ability of pesticide users and other stakeholders to make informed decisions through knowledge of compliance history of non-compliant manufacturers/distributors/vendors/ users, etc.;

- Improved compliance of regulated parties and increased understanding of regulatory requirements and consequences of noncompliance; and

- Demonstration to the public that the regulator's efforts in postmarket surveillance and vigilance in monitoring its regulated community are working.

Regulatory authorities should consider the following to determine an appropriate length of time for compliance and enforcement records to be kept on the website:

- Country-specific guidance/standards on the length of time government records are kept on file;

- Corrective actions taken by the contravener; and

- Relevance of the posted situation of non-compliance to impact present and future compliance of the contravener or other regulated parties.

\subsubsection{Communicating with regulators in other countries}

Regulatory authorities are also encouraged to inform other member countries of relevant situations of non-compliance to raise awareness and assist in identifying potential situations of non-compliance in other member countries and selecting appropriate compliance and enforcement actions (e.g. alerting other countries when counterfeit pesticides are detected). For instance, European Union Member States will be required ${ }^{2}$ to inform other members when it withdraws or amends an authorisation effective 14 June 2011 (European Union, 2009). The OECD is also developing an integrity information sharing system for its members.

It is important that compliance decisions that could impact other stakeholders be clearly documented and that a summary of the decision rationale be made available to stakeholders. Such decisions are important not only for the regulated community, but also for regulators to learn from the decisions made in other countries. Regulators may face similar challenges and the ability to see how it was addressed elsewhere can 
be very beneficial. Thus, summaries of specific risk-management issues should be made publically available on the originating country's website, drafted in such a way to eliminate the identification of specific individuals where such disclosure is not legally permitted. The public can also benefit from these decisions by being able to make informed product choices. Where serious risks are confirmed, public advisories should be considered through various forms of media distribution. Informing the regulated community of compliance and enforcement actions is essential in building a culture of compliance whereby regulator decisions are respected and individuals can make informed pesticide choices and understand their legal obligations.

\section{Notes for Chapter 4}

1 Due to differences in circumstances (e.g. products, companies, available information, etc.).

2 EU Regulation (EC) No. 1107/2009, Article 44(4).

\section{Reference for Chapter 4}

European Union (2009), Regulation (EC) No. 1107/2009, http://eur-lex.europa.eu/ LexUriServ/LexUriServ.do?uri=OJ:L:2009:309:0001:0050:en:PDF. 



\section{Chapter 5}

\section{Evaluation of Effectiveness}

Actions taken to restore compliance should be evaluated to determine if they achieved their desired effect. If the initial compliance and enforcement response was not successful in achieving timely compliance, an escalated enforcement approach should be used. Those situations where a lack of will is exhibited in complying will generally require closer scrutiny than those where a lack of knowledge was the cause of non-compliance.

Where a lack of ability to comply exists, there is an added burden on the regulator to determine whether the requirements are too restrictive. If they are not, the regulator should look at solutions to address the problem. Where the restrictions are necessary but cannot be met, the regulator may consider prohibiting further manufacturing of the product, including cancelling any approvals for this product, prohibiting further distribution, transportation, sale or use of the product, etc.

A tracking system of non-compliant cases with a "bring forward" mechanism to identify the need for and timing of follow-up surveillance activities (i.e. to re-inspect for compliance) is beneficial. For example, in the manufacturing sector, follow-up activities or actions can include:

- Request for batch data, sales records from source providers and invoices for imports;

- Targeted or random on-site inspections;

- Sample analysis of start-up products or commercially sold products;

- Review of incident reports in relation to corrective actions taken;

- Review of certifications gained; and

- Review of QA/QC processes developed and implemented. 
Lessons learned should be reported and shared with relevant stakeholders. Management should ensure that the knowledge obtained through the evaluation process is utilised and incorporated into future compliance and enforcement actions. Identifying and communicating the negative outcomes that were likely prevented as a result of the enforcement action(s) taken is one effective way to report results. 


\section{Annex A}

\section{Manufacturing}

\section{A.1. Regulatory requirements and compliance and enforcement activities ${ }^{1}$}

Citizens, non-governmental organisations, regulators and consumers / users of pesticide products have expectations that pesticide products are manufactured in such a way that there is not an unacceptable risk when used properly (i.e. by following the label directions).

For the purpose of this document, maintaining product integrity refers to ensuring that a product is consistently produced (i.e. it is what it claims to be) and that other prohibited or unsafe substances are not introduced into the product. To maintain product integrity, the product must conform to the established specifications and regulatory requirements.

The manufacturing of pesticides, for both active ingredients and enduse products, is generally governed by a range of regulatory requirements and industry procedures and practices to help to ensure product integrity. Evidence of product integrity may need to be demonstrated through a pre-market approval process and may be required on an ongoing basis as established by the policy or legislation of the regulator. It is important to note that some variations in product manufacturing may be tolerated when they do not pose an unacceptable risk, such as setting limits for the presence of specific contaminants of toxicological concern (e.g. at the parts per thousand level). 


\section{A.2. Problem identification ${ }^{2}$}

\section{A.2.1. Types of problems and possible root causes}

Actions taken by the manufacturer can have significant impacts on the chemical composition of a product and may require review/approval by the regulatory authority. There can be a number of product integrity problems/issues that may occur during the manufacturing process that result in non-compliance of the product with the expected or approved product requirements including:

- A change or substitution of an ingredient including changes to:

- start-up materials used in the manufacturing of an active ingredient/substance

- identity of the active ingredient/substance in an end product

- source or origin of an ingredient

- purity of the active or another ingredient

- amount or proportion of ingredients

- formulation

- formulation type (solid, liquid, etc.)

- A change in manufacturing process including changes to:

- quality management procedures

- labelling (old labels, label placed on wrong product, missing components)

- Contamination by a product made previously using the same equipment

To minimise the risks of product-integrity problems, manufacturers should consult with the requirements of regulatory authorities for those actions and changes that require approval.

The following list identifies many of the underlying reasons or root causes of why a product integrity issue may/does exist at the manufacturer level:

- Wilful modification of a product for economic gain (e.g. cheaper ingredients, lack of available ingredients/registered active sources (as applicable), reduced/replaced active or other more costly ingredients). Note: a recession can often disrupt supply chains; 
- Unknowingly using contaminated starting materials;

- Inadequate QA/QC control measures due to costs, lack of expertise or lack of effort (incorporating reworked products, cross contamination, inappropriate micro-contaminant testing equipment, lack of testing, untrained staff);

- Lack of registrant oversight of hired/contract manufacturer;

- Research deficits in assessing identity, purity and potency resulting in the misidentification and quantification of product composition;

- Lack of validated analytical methods and reference materials of unknown purity and/or stability;

- Problems with sample handling;

- Lack of staff training; and

- Lack of necessary equipment related to cost benefit.

\section{A.2.2. Compliance monitoring and verification}

A number of mechanisms can be employed to effectively verify manufacturer compliance. In addition to those listed below, established systems of quality and inspection, such as the ISO 9000 family (International Standards Organization, 2011) and the International Council of Chemical Associations' Responsible Care (International Council of Chemical Associations, 2011) voluntary initiative, may also provide applicable best practices in verifying compliance in the pesticidemanufacturing area.

\section{A.2.2.1. Identifying, monitoring and analyzing manufacturers}

Systems to monitor manufacturer compliance can include: incident reporting by manufacturers, complaints (adverse effects on crops, lack of pest control, etc.), assessment of sales records and import records, and licensing/certification frameworks.

Maintaining a list of manufacturers and the number and type of products that they make along with details pertinent to their QA/QC procedures provides a beneficial way of identifying manufacturers for risk-based monitoring. Regulatory authorities may wish to identify new manufacturers from contact-management databases. It may be difficult 
to maintain accurate and current information as the manufacturers and suppliers of ingredients change.

Certain regulatory regimes find that a mandatory system in which a manufacturing establishment or facility is issued a permit/licence is an effective approach for keeping current inventory of all sites. This inventory facilitates any subsequent inspection of these sites to either check documents (to verify what ingredients are being purchased/used) or the site where ingredients are stored, and where pesticide products are actually made. It should be noted that the inspection of documents can help to verify that unapproved ingredients (active substances or other ingredients) are not being imported or used in violation of regulatory requirements. The inspection of sites is also useful in verifying that documents or records are consistent with what is being done in the manufacturing process.

\section{A.2.2.2. Review of data/information}

The systematic review or audit of information provided by manufacturers to regulatory officials can be an effective tool for detecting unreported changes of product ingredients. However, the success of this method of verification relies on the full and truthful disclosure of information by manufacturers. This practice has limitations where the manufacturer and regulatory authority are located in different countries.

Where the authority exists, regulators may also request manufacturers to submit chemical-analysis results of recently manufactured batches to compare their composition to the approved product composition. This provides an opportunity to identify unexpected changes in proportions of the ingredients or introduction of unapproved ingredients/contaminants which may or may not present toxicological concerns. It may be helpful to alert other regulators (e.g. regulators in other countries) that there may be problems with the composition of a pesticide, based on the results of analyses, without the disclosure of protected or confidential business information. 


\section{A.2.2.3. On-site review/inspection}

Another mechanism that is often used is on-site verification, which works best when it is done periodically, but at random or varying intervals. On-site inspections of manufacturing facilities allow for any operational requirements or best practices in relation to product development and management to be assessed and analyzed from a compliance and risk perspective. Inspections are opportune times to check pesticide labels and packaging, storage areas and spill containment, cleaning and contamination control measures, quality control measures, batch/lot tracking, invoice/import records, training and equipment provided for employees, accreditations, etc.

There are challenges associated with conducting on-site inspection programs to verify compliance when products are manufactured abroad. In some countries, industry-developed voluntary codes or BPs may serve as suitable surrogates for inspections conducted by regulators. Regulators should be able to discuss with manufacturers their analytical methodologies in order to be able to confirm product integrity details upon request. In addition, the exchange of information between regulatory officials (without the disclosure of protected or confidential business information) can assist in the evaluation of compliance. For example, if the authority and mechanism exists, a regulator may seek the assistance of regulatory officials in another country regarding site inspection information of a particular manufacturer.

\section{A.2.2.4. Off-site inspections}

Off-site inspections can include checking product guarantees, presence/level of impurities/micro-contaminants of concern, product expiration (stability) and confirming replacement of ingredients that may be phased out due to risk-based concerns.

\section{A.2.2.5. Quality control}

Minimal quality standards should be established by regulators and confirmed through inspection or paper-based exercises. Manufacturers should establish a quality control system to help ensure that starting materials, intermediates, finished pesticides and packaging materials conform to established specifications for identity, strength, purity 
and other characteristics. A quality control unit independent of manufacturing is preferable given the potential conflict of interest in wanting to release a product into the market.

Regulators can also encourage manufacturers and formulators to conduct proficiency testing. Proficiency testing is the use of interlaboratory comparisons (two or more labs) to determine the performance/ competency of individual laboratories for specific tests, measurements and calibrations. Proficiency testing programs allow the industry to objectively assess and demonstrate the reliability of data produced, and identify areas where improvement in testing and measurement methods are needed.

\section{A.2.2.6. Importation controls}

A regulator may consider establishing working agreements with their border officials to aid in the detection and prevention of illegal importation of pesticide ingredients/products that do not meet the country's legal requirements. Clearly preventing such imports can reduce the burden on regulators to detect and address non-compliance over a much larger scale as products proceed along the distributor/retail/user chain. Establishing border partnerships can require additional funding and will require periodic training of border officials so that they are aware of the regulator's requirements and products of concern.

\section{Notes for Annex A}

1 This section should be read in conjunction with Chapter 2 of the main document.

2 This section should be read in conjunction with Chapter 3 of the main document. 


\section{References for Annex A}

International Council of Chemical Associations (2011), Responsible Care, www. icca-chem.org/en/Home/Responsible-care/.

International Standards Organization (2011), ISO 9000 essentials, www.iso.org/iso/ iso_catalogue/management_and_leadership_standards/quality_management/ iso_9000_essentials.htm. 



\section{Annex B}

\section{Distribution}

\section{B.1. Regulatory requirements and compliance and enforcement activities ${ }^{1}$}

Transporters, distributors and vendors involved in the distribution, transportation and sale of pesticides are generally governed by a range of regulatory requirements to minimise the associated health and environmental risks.

The role of the regulator is to ensure that regulatory requirements during pesticide distribution, transportation and sale are met by the regulated parties. These requirements may detail the authorisation(s) required to transport or sell pesticides, as well as what types of pesticides can be sold and to whom.

While specific regulatory requirements will vary by country-specific legislation and associated regulations, the following examples of best practices can minimise health and environmental risks:

- Limit selling of pesticides to registered vendors;

- Require that pesticides are registered and appropriately labelled prior to sale;

- Require that staff are properly trained on the proper transportation, sale and storage (during sale) of pesticides;

- Require vendors to maintain sales records documenting that the products sold are registered and are sold in accordance with any limitations required as a condition of the registration; 
- Require transporters and distributors to maintain delivery documents, including the amount of pesticides, the bulk number and the correct name of the pesticides;

- Require vendors to lock storage rooms (i.e. pesticides should be inaccessible to the public as required by regulations);

- Require vendors to dispose of or return obsolete pesticides (e.g. products that are phased out or authorisation/registration revoked) to the distributor or manufacturer;

- Require vendors to separate different pesticides at storage (e.g. separate storage of herbicides and other pesticides, separate storage of pesticides which are not registered at the moment or which are intended for export). In order to minimise hazards, particularly for large volumes, pesticides should be stored in groups corresponding to different hazard categories (e.g. flammability, combustibility, corrosivity, etc.). Guidelines are given in "Guidelines for the safe warehousing of crop protection products" (CropLife International, 2007);

- Establish maximum amounts of pesticides permitted to be transported or stored as well as the packaging and storage conditions that should be followed; and

- Repackaging of a pesticide is not allowed unless the regulator authorises such repackaging either as part of the approval of the pesticide, or allows a party to undertake this activity under special circumstances without a specific approval.

To facilitate compliance with these standards and best practices, the regulator may:

- Communicate information to vendors related to the registration status (e.g. withdrawal of authorisation);

- Provide label information publically (e.g. on an official website); and

- Inform/warn distributors about the existence of illegal products and provide information on how they can be detected. 


\section{B.2. Problem identification ${ }^{2}$}

\section{B.2.1. Types of problems and possible root causes}

A range of problems can occur during the transportation, distribution and sale of pesticides, including:

- Distribution or sale by unauthorised/uncertified distributors or vendors;

- Lack of documented chain of custody (i.e. the origin of a pesticide is not obvious);

- Improper declaration during importation;

- Repackaging of individual packages or dilution and sale of products;

- Improperly shelved pesticides (e.g. near food, feed, drink or within reach of children);

- Incomplete, incorrect, damaged or missing labels;

- Leaking or damaged containers;

- Sale of unregistered or counterfeit products;

- Sale to unqualified users (e.g. sale of a commercial-grade pesticide to a consumer);

- Sale of expired products;

- Lack of information provided by vendors on the correct use (pests, locations, timing);

- Misleading advertising of product related to product safety or efficacy; and

- Missing sales records.

The following list identifies many of the underlying reasons or root causes of why a problem may/does exist at the distribution, transportation or sales level:

- Wilful distribution, transportation or sale of an illegal product for economic gain;

- Lack of interest or suspicion (e.g. a transporter or distributor may not question the legality of a pesticide);

- Inadequate/insufficient knowledge or training of truck drivers, dock workers or warehouse workers regarding the proper transportation of pesticides and the ability to detect illegal pesticides; 
- Inadequate/insufficient control measures due to costs, lack of expertise or lack of effort at borders, reloading points, retailers and end-user level (lack of staff, untrained staff); and

- Lack of registrant oversight of hired distributor or transporter.

\section{B.2.2. Compliance monitoring and verification}

It is very difficult to estimate the actual prevalence of non-compliance in the area of pesticide distribution, particularly when there is low traceability (e.g. when pesticides are delivered directly to users by mail order), as the identification and verification of non-compliance may depend largely on suspicions or information from other parties. In addition, detecting the distribution and sale of unregistered and counterfeit pesticides can be particularly challenging for the following reasons:

- Additional storage rooms may exist besides exhibited storage rooms;

- Unregistered or counterfeit pesticides may only be sold to close business partners;

- Counterfeit pesticide packages may look like original registered packages and may only be detectable by chemical analysis;

- Delivery receipts may indicate the name of registered pesticides when illegal pesticides are actually delivered.

Inspections, product sampling and border oversight are useful approaches to help monitor compliance with requirements related to the distribution, transportation and sale of pesticides.

\section{B.2.2.1. Inspections}

The following types of inspections are useful to monitor compliance:

- Marketplace inspections, test purchases and monitoring of sales records to ensure only registered products are sold/offered for sale;

- Inspection of transport systems for compliance with regulations including hazardous goods regulations; and

- Inspections during transportation or at transportation points (e.g. re-loading points, border). 


\section{B.2.2.2. Product sampling}

The regulator should sample pesticides on the market to ensure that they are in compliance with the defined quality of the registration. If they are not compliant, it could point to a problem related to distribution. It is sometimes necessary to compare the compositions as defined in the registration documents. This control takes into account information about production sites of the active ingredients/substances and formulations. Therefore, regulators from different countries should share this type of information upon request.

Cooperation with other regulatory authorities can provide valuable information related to the specifications and composition of active ingredients/substances and pesticides.

\section{B.2.2.3. Border monitoring of imported and exported pesticides}

Authorities must work together to monitor and verify compliance of pesticides that are imported and exported, including customs offices and regulators (both registration officials and compliance and enforcement officials) in the countries of origin and destination. International agencies, such as Interpol, can work across borders and observe trade flows.

Regulators should provide information about active ingredients/ substances and pesticides produced/manufactured and exported from their countries to regulators in destination countries, including any knowledge about the production and export of counterfeit pesticides (e.g. addresses of registration holders, facilities, composition of product). Compliance monitoring and enforcement in the area of internet trade and mail order trade can be very difficult, and improved international cooperation and communication in this area can be particularly helpful.

Since the original name of pesticides is not always given on delivery documents, an inspection of the original package and in some cases, a sampling and analysis of the pesticides may be useful. Border control officials in the destination country can support compliance and enforcement activities by verifying that:

- The recipient is a registered wholesaler, retailer, producer or a formulation company; 
- The active ingredient/substance is authorised in the recipient country; and,

- The pesticide is registered in the recipient country.

If non-compliance is suspected, appropriate delivery documents (amount, product name, active ingredient/substance) should be forwarded to the regulator.

\section{Notes for Annex B}

1 This section should be read in conjunction with Chapter 2 of the main document.

2 This section should be read in conjunction with Chapter 3 of the main document.

\section{Reference for Annex B}

CropLife International (2007), Guidelines for the safe warehousing of crop protection products, www.croplife.org/view_document.aspx?docId $=415$. 


\section{Annex C}

\section{Storage}

\section{C.1. Regulatory requirements and compliance and enforcement activities ${ }^{1}$}

Many pesticides are (or contain) chemicals that have hazardous attributes, such as toxicity, corrosiveness or flammability. To minimise the risks associated with those hazards, they must be handled, stored and used with care. Correct storage of pesticides is necessary to protect people, particularly workers, animals and the environment. Better practices in storage prolong the shelf life of products and secure storage can assist in preventing theft or inappropriate access. Inappropriate storage conditions that affect the pesticide may cause economic losses to users due to lack of efficacy or damage to crops and to manufacturers or distributors due to complaints and negative publicity.

The actual requirements for storage of pesticides will depend on the types and amounts of pesticides being stored, the number and nature of any other chemicals at the storage location, and the stage at which storage is occurring in the distribution chain. Commercial transport firms, agricultural supply stores, farmers and home gardeners are all likely to have different needs.

The following subsections outline some best practices related to pesticide storage.

\section{C.1.1. Suitability of storage locations}

The following general principles apply when assessing the suitability of locations for pesticides storage areas: 
- All local government zonings and other ordinances are to be observed;

- Local environmental conditions are to be considered (level of water table, possibility of flooding, etc.);

- Storage area(s) are to be accessible to emergency services under all foreseeable weather conditions; and

- Storage areas for flammable and combustible liquids are to be at or below ground level.

\section{C.1.2. Major and minor storage facilities}

At higher levels in the distribution chain, larger quantities and a wider range of pesticides may be stored. Such larger volumes may be subject to particular regulation as major environmental hazards. For larger quantities of pesticides, the preferred storage option is an isolated, stand-alone building only containing chemicals. This is often similar to how paints, fuels and other flammable products are stored.

The construction of a designated storage area for pesticides may be:

- A free-standing, roofed building;

- An outdoor storage area with a security fence that may have a roof;

- A room, enclosure or area within a building; or

- A building that is attached to another building.

For storage of minor quantities where a separate area is not available, the following general principles should be followed. These general principles are also applicable to purposed designed facilities. A minor storage area should:

- Be fire resistant and structurally sound;

- Have concrete floors or similar material which is impervious and resistant to chemical erosion;

- Be protected against extreme heat and exposure to sunlight;

- Include bunding (containment) or other method of containing spills;

- Be able to be locked; 
- Be located in an area that is safe from flooding or inundation, and not in the immediate catchment of a dam or waterway;

- Have clear access to avoid hazards while carrying chemicals;

- Have sturdy, non-absorbent shelving that is adequate to store chemicals without excessive stacking;

- Fully protect chemicals from the weather as chemical containers and their contents can be damaged by exposure to moisture, direct sunlight and extreme temperatures; and

- Have adequate ventilation to prevent vapour build up by allowing vapours to escape readily (this may include the use of ventilation systems).

Separate free-standing buildings and proper design will result in a lesser risk of contamination if any spills or accidents do occur. Freestanding buildings also provide easier access for loading, unloading and dealing with any incident such as fire or a major spillage.

Pesticide storage areas should be located a distance from certain types of buildings or property features to prevent exposure or releases in case of a fire or a major spillage. For example, in Australia, pesticide storage areas should be located:

- At least $\mathrm{I} 5 \mathrm{~m}$ from the boundary property, io $\mathrm{m}$ from buildings occupied by people or livestock, $3 \mathrm{~m}$ from unrelated work areas, offices and amenities; and

- At least $3 \mathrm{~m}$ from flammable materials and fuel storage, $5 \mathrm{~m}$ from any watercourse, body of water, drain or sewer (Australian Standard, 1998).

These distances are regarded as the minimum distances for minor storage. For larger storage facilities, greater distances should apply. If subject to particular regulation, such as major environmental hazards, all specified minimum distances are to be observed.

Storage of pesticides and chemicals in a partitioned section of a multi-purpose building is acceptable, although not preferred. It is important that this building is not ordinarily used for human or animal habitation. Small quantities of chemicals may be stored in a steel cupboard within a multipurpose building that is not used for human or animal habitation, such as garden sheds. Pesticides must not be kept in occupied houses or houses expected to be occupied by people. 
Furthermore, pesticides must not be kept in containers intended for other uses, especially not in food/drink containers.

\section{C.1.3. Security and inventory management}

In a setting where large quantities of pesticides are stored, strict inventory management should be practised. The following is recommended:

- Unauthorised personnel are not permitted access the storage area;

- Accompany persons other than employees at all times and brief them on the hazards present;

- Utilise placards to increase staff awareness of particular characteristics, such as hazard, purchaser control, storage compatibility;

- Computerised inventory controls should reflect these particular characteristics, such as purchaser controls;

- Group classes of pesticides with particular hazards or characteristics on a 'like with like' basis (e.g. store rodenticides away from other pesticides or in air-tight vessels to prevent odour transfers);

- Consider storage compatibility for pesticides with conflicting or potentiating hazards, and co-location avoided;

- Distinctly store pesticides subject to specific purchaser controls and sign with placards accordingly;

- Where pallets of pesticides are stored, configure shelving so as to prevent "over-stacking" beyond the recommendations for the particular pesticides and chemical containers;

- Avoid potential sources of ignition and heat such as naked flames, matches and lighters, exposed incandescent material and welding and cutting activities in pesticides storage areas; and

- Do not permit smoking within $3 \mathrm{~m}$ of a storage area containing pesticides (Australian Standard, 1998).

In an end-use setting, all pesticides and chemical containers should be kept in storage when they are not being used. The chemical store should be locked when it is not attended. A storage area that is part of an enclosed multi-purpose building or a storage cupboard within such a building should all be separately secure to prevent unauthorised access even when the rest of the building is open. 
End users should read and comply with storage instructions on product labels and try to keep pesticides in their original containers with the labels intact. At all times, pesticides must be kept in a suitable container clearly marked or labelled with the name of the product and the name and concentration of each of the active constituents of the product. Food or drink containers are never to be used to store pesticides. Pesticides must be stored so as to prevent accidental interaction or contamination. Other than limited quantities for domestic use, pesticides must not be stored near foodstuffs, foodstuff packaging and medical/first aid supplies.

\section{C.1.4. Containment of spills}

Pesticides storage facilities are to be designed, located and constructed so that environmental damage is unlikely to occur. Spillage or leakage of pesticides must be contained within the storage facility by any one of the following:

- Impervious floor resistant to chemical attack, such as concrete, with integrated perimeter bunding;

- Impervious floor resistant to chemical attack, which is sloped to a collection area so that, in event of a fire, molten chemicals are safely diverted into a suitable area for disposal;

- Use of portable bunding; and/or

- No drain/outlet to the general sewage system.

All bunding material must be resistant to chemical attack.

A Spill Response Kit should also be maintained in every pesticides storage area. The kit should include some readily available material and equipment to contain, absorb and decontaminate spilt chemicals. The kit used for containing spills should be capable of containing $25 \%$ of the total liquid stored. A spill kit containing the following materials is recommended and should be kept in the storage area:

- Absorbent material (e.g. dry soil or kitty litter);

- Hydrated lime;

- Soda ash;

- Liquid industrial detergent; 
- Shovel and broom;

- Decanting tap, siphon pump and funnel;

- Containers for storage of contaminated substances used to treat a spill; and

- Clean and empty containers that can be used to receive chemicals from leaking containers.

A spill response plan, including contact lists and clean-up procedures, should accompany the spill response kit, and personnel should be trained on the procedures and the use of materials in the spill response kit.

\section{C.1.5. Other best practices}

There are a number of other mechanisms that can be used to help manage the storage risks of pesticides.

\section{Warning signs}

Warning signs are necessary to indicate that the facility is a pesticides storage area. As pesticides and other chemical substances may be flammable, dangerous or have particular hazards, appropriate label sign(s) and a sign prohibiting fire, naked flame and smoking must be displayed.

\section{Water supply}

A water supply should be available for emergency use to wash the skin or flush the eyes of a person suffering from chemical contact. The emergency water supply should be capable of supplying at least 15 minutes of continuous flow. A water supply is also useful for general cleaning and washing.

\section{First aid kit}

A basic first aid kit and an eye module are recommended for any worksite where pesticides are present. 
Fire extinguisher(s)

A fire extinguisher approved for chemical fires should be readily available.

\section{Personal protective equipment}

Personal protective equipment (PPE), appropriate for the types of chemicals being stored, should be readily accessible and separately stored at the facility. PPE is not to be located directly with the chemicals. It is often convenient to place PPE at entry and exit points of the facility, or in any changing area used by staff working at the facility. Workers should read the label for directions on PPE that is required when handling the product.

\section{Records}

In addition to the other inventory controls, a store manifest and site plan should be available to emergency services in case of emergency, such as a fire. For all of the products in storage, a safety data sheet should be accurately maintained for the facility. Records should be kept of any injuries or accidents.

In order to prevent serious incidents, staff should only work in pairs or at least within shouting distance of other personnel.

\section{C.2. Problem identification ${ }^{2}$}

\section{C.2.1. Types of problems and possible root causes}

Possible problems that may occur during pesticide storage include:

- Use of improvised storage areas;

- Improperly stored or shelved pesticides;

- Leaking or damaged containers;

- Damage or loss of labels during transport;

- Catastrophic failure or fire;

- Environmental contamination or damage. 
The following list identifies many of the underlying reasons or root causes of why a pesticide storage problem exists:

- Lack of or decrease in storage space (particularly in densely populated areas);

- Lack of appropriate buildings for storage;

- Elevated stock levels;

- Uncontrolled storage (i.e. damage from lack of temperature control or lack of protection from precipitation);

- Lack of knowledge or training related to proper storage (particularly by the end user);

- Misunderstanding or misinterpretation of label storage information;

- Failure to detect leaking or damaged containers;

- Damaged or loss of labelling during transport;

- Unforeseen transport or distribution problem; or

- Deliberate disregard of storage requirements.

\section{C.2.2. Compliance monitoring and verification}

Assessing storage during inspections that might have been targeted towards other problems such as pesticide use, is an effective method to monitor compliance with storage requirements.

Accidents or injuries may highlight a storage management or noncompliance problem.

Complaints related to product integrity concerns may be due to incorrect storage conditions (e.g. extreme temperatures).

The most likely and common methods of detecting pesticide storage problems are complaints from neighbours/competitors or observations.

\section{Notes for Annex C}

1 This section should be read in conjunction with Chapter 2 of the main document.

2 This section should be read in conjunction with Chapter 3 of the main document. 


\section{Reference for Annex C}

Australian Standard (1998), AS 2507-1998: The Storage and handling of agricultural and veterinary chemicals. 



\section{Annex D}

\section{Use}

\section{D.1. Regulatory requirements and compliance and enforcement activities ${ }^{1}$}

For the purpose of this document, best practice for use of pesticides relates to the use of the pesticide to ensure they do what they are intended to do (i.e. control the pest without damaging the target crop), minimise environmental and human health issues, and ensure residues in foods are compliant with domestic residue standards. The role of the regulator from a compliance perspective is to ensure that pesticides users follow the label directions.

The use of pesticides is generally governed by a range of regulatory requirements and industry procedures and practices to help ensure that the product is used appropriately. Evidence of this may need to be demonstrated through a pre-market approval process and may be required on an ongoing basis as established by the policy or legislation of the regulator.

Due to the fact that the number of pesticide users can be very large, one of the most effective methods of ensuring compliance with use requirements is compliance promotion.

\section{D.2. Problem identification ${ }^{2}$}

\section{D.2.1. Types of problems and possible root causes}

There can be a number of problems that may occur during pesticide use, including:

- Users not following label directions and examples of these are:

- $\quad$ wrong application rate applied

- $\quad$ used on crops or against pests not stated on the label 
- re-entry period into sprayed crop not followed

- crop withholding period not followed

- restrictions on how and where the product can be used

- health and safety requirements on the label not followed

- Out of date practices

- end-user competency

- lack of necessary user training

- user lacks understanding of legal requirements

- Equipment is not fit for purpose

- application equipment or personal protective equipment not maintained

- application equipment not used as per the manufacturer's instructions

- Label quality issues

- instructions on labels not clear

The following list identifies many of the underlying reasons or root causes of why a pesticide-use issue may/does exist:

- Users are not well educated, lack training or lack knowledge of the main language used in the country (i.e. the language on the label);

- Lack of appropriate products means users may use other products off label;

- Economic reasons to reduce costs by users meaning they use products at rates lower than recommended on the label, and/or do not maintain their equipment;

- No training courses available to train users in correct use of products;

- Lack of understanding by regulators and manufacturers of best practice in a industry sector which is reflected on the label; or

- Poor knowledge of legal requirements by users. 


\section{D.2.2. Compliance monitoring and verification}

There are a number of mechanisms that are effective in detecting use problems and verifying compliance.

\section{D.2.2.1. Identifying and analyzing use of pesticides}

Systems to monitor compliance in this area can include incident reporting by manufacturers, complaints (adverse effects on crops, lack of pest control), assessment of spray records and training/certification frameworks.

\section{D.2.2.2. Review of data/information}

The systematic review or audit of information provided by manufacturers to regulatory officials can be an effective tool for detecting unreported information which may have an impact on what information goes on the label. However, the success of this method of verification relies on the full and truthful disclosure of information by manufacturers. This practice has limitations where the manufacturer and regulator are located in different countries.

\section{D.2.2.3. User proficiency}

Requiring a training scheme/program (or equivalent) of end users may reduce the level of non-compliance by end users. Such schemes/ programs should include understanding of terminology, correct use and maintenance of equipment, legal obligations, and how to read and understand a label.

The level of regulatory oversight of such schemes/programs can be flexible to meet their country's requirements. This could include direct involvement (i.e. undertake training in order to become an auditor of a third party undertaking the training scheme).

There are a number of options to determine the proficiency and training of end users, including:

I. Audits of training schemes/programs for end users can be used to ensure users are being trained adequately in the use of pesticides. Such audits can focus on the training material to ensure it: 
- covers the current legislation including any amendments

- includes the up-to-date best practices for applying pesticides

- covers terminology and understanding of labels

2. Audits of end-users' spray records can be used to determine their proficiency in the use of pesticides.

\section{D.2.2.4. Labelling}

The manufacturer of the product and the governing regulatory authority should ensure the label is clearly written and provides useful information on the following areas:

- Health and safety for the user and others;

- Environmental safety;

- Directions for use;

- Withholding periods;

- Storage, transportation, handling and disposal; and

- Regulatory compliance statements.

\section{Notes for Annex D}

1 This section should be read in conjunction with Chapter 2 of the main document.

2 This section should be read in conjunction with Chapter 3 of the main document. 


\section{Annex E \\ Container Recycling and Disposal}

\section{E.1. Regulatory requirements and compliance and enforcement activities ${ }^{1}$}

Empty pesticide containers must be managed properly to minimise risk to both humans and the environment. The FAO document, Guidelines on Management Options for Empty Pesticide Containers ${ }^{2}$ (2008), identifies the following goals for a container management scheme:

- The containers should be decontaminated and punctured directly following the use of their contents;

- Inappropriate use of the empty containers should be prevented; and

- It should be easy for users to return their empty containers to the scheme.

While a detailed discussion of the logistics of a container management scheme to collect and recycle or dispose of the containers is beyond the scope of this document, participation in a container management scheme by pesticide end users, manufacturers, distributors and container recyclers is voluntary in many countries. In Mexico, the establishment of container management plans has been effective in increasing the recovery level of empty containers. The return of empty pesticide containers to a container management scheme could be motivated and increased by a deposit system. Alternatively, participation and the amount of containers returned could be increased by requiring end users to participate or by obligating manufacturers and/or distributors to take back or facilitate collection of empty containers. 
The following subsections describe best practices related to container recycling and disposal.

\section{E.1.1. Rinsing and puncturing}

Regardless of whether the container will be recycled or disposed of, it is essential that the container is properly rinsed directly after it is emptied if it held a pesticide (liquid or solid) that is intended to be diluted with water or another material as part of its use. The key points for properly rinsing pesticide containers are:

- The container should be rinsed immediately after the container is emptied.

- The containers should be thoroughly rinsed by triple rinsing or pressure rinsing. Triple rinsing involves adding a specified amount of water to the container, shaking or agitating the container, pouring or pumping the rinsate into the application mixture, and repeating this two more times. With pressure rinsing, a nozzle or wand that is attached to a water source is inserted into the container and used to spray pressurised water around the interior of the container. Countries probably have their own definitions of these procedures. The procedures in the United States for rinsing containers that hold dilutable liquid pesticides are included here as examples. The procedures for rinsing containers that hold dilutable solid pesticides are similar, except it is not necessary to drain the remaining contents for 10 seconds. It is generally easier to completely remove granules from a container compared to powder formulations.

- Clean container promptly after emptying. Triple rinse as follows: Empty the remaining contents into application equipment or a mix tank and drain for 10 seconds after the flow begins to drip. Fill the container $1 / 4$ full with water and recap. Shake for 10 seconds. Pour rinsate into application equipment or a mix tank or store rinsate for later use or disposal. Drain for 10 seconds after the flow begins to drip. Repeat this procedure two more times.

- Pressure rinse as follows: Empty the remaining contents into application equipment or a mix tank and continue to drain for 10 seconds after the flow begins to drip. Hold container 
upside down over application equipment or mix tank or collect rinsate for later use or disposal. Insert pressure rinsing nozzle in the side of the container and rinse at about 40 PSI for at least 30 seconds. Drain for 10 seconds after the flow begins to drip.

- At the end of the rinsing process, the containers should be thoroughly drained to remove as much rinsate as possible to prevent water leaking during the transport and collection of the containers. In addition, plastic recyclers may offer a higher price for plastic flakes that are dry because dry material is easier to handle and process.

- After containers are thoroughly rinsed, the containers should be rendered unusable by puncturing, slashing or crushing them.

- As recommended by FAO, properly rinsed and inspected containers should be classified as non-hazardous waste, which will facilitate the ease of recycling.

\section{E.1.2. Managing the containers}

Empty pesticide containers must be managed properly to minimise risk to both humans and the environment.

It is generally preferable to recycle properly rinsed metal and plastic containers as new products rather than to dispose of them by high temperature incineration (for plastic containers) or landfilling. Incineration should be carried out with the intention of energy recovery, if possible (e.g. in a cement kiln). Open burning or other methods of disposal should not be used.

During the recycling of metal containers, the metal is melted at high temperature, which is sufficient to destroy pesticide residues. Therefore, there are no concerns about the materials or objects that are produced from recycled metal pesticide containers. On the other hand, recycling plastic containers presents several challenges. First, plastic melts at a substantially lower temperature than metal. The level of pesticide residues in containers should be low after rinsing, although small amounts of residues may still be present in the plastic through migration. Therefore, the end use plastic coming out of the recycling process should be known and approved and limited to uses with minimal human 
contact. Also, plastic pesticide container recycling programs often have many logistical steps like sorting different types of plastic and removing paper labels, foil seals and possibly the caps from the containers. This is done because different types of plastics melt at different temperatures and contaminants such as paper, other types of plastic or other materials can decrease the value of the processed plastic.

High temperature incineration with proper process and emissions controls allows plastic containers and pesticide residues to be completely destroyed with minimal emissions to the environment. Open (uncontrolled) burning on farms takes place at a much lower temperature. At these lower temperatures, the hazardous components are not completely destroyed and toxic materials may be emitted. Open burning must, therefore, not be used.

\section{E.2. Problem identification ${ }^{3}$}

\section{E.2.1. Types of problems and possible root causes}

The following types of problems can occur when empty pesticide containers are not managed properly:

- Reusing pesticide containers for storing food or water could result in pesticide exposure and poisoning of humans or animals;

- Abandoning unrinsed containers in the environment could lead to pesticide contamination in the soil, surface water or ground water;

- The residue in unrinsed containers could expose people, soil or water to pesticides during the collection and transport of the containers for recycling or disposal;

- Not rinsing containers increases the cost of recycling or disposing of containers, because most countries regulate rinsed containers as non-hazardous waste and unrinsed containers as hazardous waste;

- If a container is not rinsed immediately after it is emptied, the pesticide may dry on the interior of the container, which makes it more difficult to remove;

- If a container is not rinsed immediately after it is emptied, the pesticide user may create a new waste that requires disposal (the rinsate) rather than using the rinsate by adding it to the 
application mixture. Rinsing containers also provides the benefits of allowing the user to gain the full value of the pesticide;

- Recycling plastic pesticide containers into articles or items other than those with minimal human contact could lead to exposure to pesticide residues in the plastic or the perception of exposure; and

- Inappropriate disposal of pesticide containers even if properly rinsed could cause a general problem of pollution by plastic/ metal waste.

The following list identifies some underlying reasons or root causes of why a pesticide container disposal/recycling issue may/does exist at the pesticide user or container recycler level:

- Choosing a disposal option (such as open burning) because it is more convenient and/or cheaper;

- Lack of access to pesticide container recycling programs;

- Lack of access to landfills because of geographic location or other constraints;

- Lack of oversight of hired container management/disposal company;

- Lack of staff training; and,

- Lack of necessary equipment related to cost benefit.

\section{E.2.2. Compliance monitoring and verification}

Assessing pesticide container recycling or disposal practices during inspections that might have been targeted towards other problems such as pesticide use is an effective method to monitor compliance with container management practices.

The most likely and common methods for detecting pesticide container disposal or recycling problems are discarded containers on or around the farm, complaints from neighbours/competitors (e.g. open burning, burying at unregistered sites, dumping) or observations during inspections for other reasons such as pesticide-use inspections. Proof (receipts or certificates) that show the user has recycled containers is an option. 


\section{Notes for Annex E}

1 This section should be read in conjunction with Chapter 2 of the main document.

2 Much of the information on pesticide container recycling and disposal is based on this FAO document.

3 This section should be read in conjunction with Chapter 3 of the main document.

\section{Reference for Annex E}

FAO (2008), International Code of Conduct on the Distribution and Use of Pesticides: Guidance on Management Options for Empty Pesticide Containers, www.fao.org/ ag/AGP/AGPP/Pesticid/Code/Download/Containers08.pdf. 


\section{Appendix I}

\section{Core Principles of Compliance and Enforcement}

Excerpt from the International Code of Conduct on the Distribution and Use of Pesticides, Revised Edition: Guidelines on Compliance and Enforcement of a Pesticide Regulatory Programme (2006), www.fao.org/WAICENT/FAOINFO/ AGRICULT/AGP/AGPP/Pesticid/Code/Download/Compliance06.pdf.

\section{Ten Core Principles}

I. Full and Continuous Compliance as the Goal

2. Culture of Compliance

3. Clear and Well-Understood Requirements

4. Expectation of Self-Initiated Compliance

5. Likelihood of Detection of Violations

6. Fair and Predictable Government Response

7. Level Playing Field

8. Message Sending and Deterrence

9. Comparable Treatment for Public and Private Sectors

Io. Transparency and Accountability 



\section{Appendix II}

\section{Glossary}

The following glossary explains technical terms used in this guidance document. The primary source of this glossary is the International Code of Conduct on the Distribution and Use of Pesticides: Guidelines on Compliance and Enforcement of a Pesticide Regulatory Programme (FAO, 2006).

Best practice A technique, method, process, incentive or reward that is more effective at delivering a particular outcome than any other; it is the most efficient and effective ${ }^{1}$ (best results) way of doing business; improving processes.

Compliance The full implementation of legal requirements.

Compliance An employee of the regulatory authority that is practitioner responsible for or involved in the operational delivery and/or program management of the organisation's mandate.

Compliance promotion

Compliance risk assessment

Compliance monitoring
Activity that encourages voluntary compliance with requirements. Examples of compliance promotion include educational programs and technical assistance.

A formal or informal process to evaluate risks as a result of non-compliance, including problem identification, probability/likelihood and impact assessments, and a classification of the overall risk.

Collecting and analyzing information on compliance status of an entity or facility or of an industry or economic sector. 
Contravener A regulated party that has failed to meet regulatory requirements. Also: Violator

Distribution Process by which pesticides are supplied through trade channels to local or international markets.

Enforcement Set of actions that governments or others take to achieve compliance by the regulated community with pesticide regulatory requirements and/or to halt situations that may endanger public health of the environment. Government enforcement usually includes activities like investigations, negotiations and legal actions

Environment Surroundings, including water, air, soil and their interrelationship as well as all relationships between them and any living organisms.

Hazard

Impact

Inspection

Label or labelling

Likelihood

Manufacturer

The inherent property of a substance, agent or situation having the potential to cause undesirable consequences (e.g. properties that can cause adverse effects or damage to health, the environment or property).

A reasonable consequence arising from the hazard.

An official review and examination of the compliance status of a facility.

The written, printed or graphic matter on or attached to the pesticide or the immediate container thereof and also to the outside container or wrapper of the retail package of the pesticide. Specific national legislation may define labelling to include additional material.

The probability that a hazard will occur. The evaluation of likelihood or probability may be expressed in qualitative or quantitative terms. Also: Probability.

Corporation or other entity in the public or private sector or any individual engaged in the business or function (whether directly or through an agent or entity controlled by or under contract with it) of manufacturing a pesticide active ingredient or preparing its formulation or product. 
Non-compliance Failure to meet regulatory requirements. Also: Violation

Pesticide

Probability

Registration

Any substance or mixture of substances intended for preventing, destroying or controlling any pest, including vectors of human or animal disease, unwanted species of plants or animals causing harm during or otherwise interfering with the production, processing, storage, transport or marketing of food, agricultural commodities, wood and wood products or animal feedstuffs or substances which may be administered to animals for the control of insects, arachnids or other pests in or on their bodies. National legislation may define pesticide more or less broadly. For purposes of this document, the national legislative definition of pesticide or pest control product is intended.

Also: Likelihood

Process whereby the responsible national government or regional authority approves the sale and use of a pesticide following the evaluation of comprehensive scientific data demonstrating that the product is effective for the intended purposes and does not pose unacceptable risks to human or animal health or the environment. Registration also refers to the licence or authorisation to sell a pesticide product following the conclusion of the registration process.

Regulated party Individuals, facilities, businesses, and/or institutions, whether private or public, that are subject to pesticide legislation and implementing regulations, licences, permits or orders. Includes, but is not limited, to manufacturers, distributors, importers, etc.

Regulator or regulatory authority
A global, regional or national governing body that establishes, monitors, reforms and enforces regulations; in this context, the regulations surrounding pesticides. 
Regulatory Risks not directly related to health, safety or environintegrity risks mental risks that are generally associated with business risks (e.g. legal liability, program integrity, regulated parties' respect for rule of law, public and stakeholder confidence).

Risk A function of the probability of an adverse health or environmental effect, and the severity of that effect, following exposure to a hazard.

Risk Level of risk assigned to a situation as a result of the classification evaluation (e.g. low, medium, high, etc.).

Risk Decision-making process involving considerations of management political, social, economic and technical factors with relevant risk-assessment information relating to a hazard so as to develop, analyze and compare regulatory and non-regulatory options, and to select and implement appropriate regulatory response to that hazard.

Risk tolerance The willingness of an organisation to accept or reject a given level of residual risk (exposure). Risk tolerance may differ across the organisation, but must be clearly understood by the individuals making risk-related decisions on a given issue. Clarity on risk tolerance at all levels of the organisation is necessary to support risk-informed decision-making and foster risk-informed approaches.

Violation Non-compliance with a requirement. Also: Non-compliance.

\section{Note for Appendix II}

1 Efficient is doing things right; effective is doing the right things. 


\section{Reference for Appendix II}

FAO (2006), International Code of Conduct on the Distribution and Use of Pesticides: Guidelines on Compliance and Enforcement of a Pesticide Regulatory Programme, www.fao.org/WAICENT/FAOINFO/AGRICULT/AGP/AGPP/Pesticid/Code/ Download/Compliance06.pdf.

\section{Reference not cited}

United States Environmental Protection Agency (2010), Labeling Requirements for Pesticides and Devices, 40 Code of Federal Regulations. 

The OECD Series on Pesticides includes documents that are developed by the OECD Pesticides Programme, that is part of the OECD work on chemical safety. Such documents include reports from workshops and seminars but also guidance documents or survey reports.

This Best Practices Guidance addresses compliance and enforcement issues as they relate to pesticides and associated health and environmental risks. The objective of this document is to provide guidance for promoting and monitoring compliance and for assessing and mitigating risks of non-compliance. It is targeted primarily at pesticide regulators, but may also interest policy makers as well as regulated parties (i.e. pesticide industry). Compliance is of high importance to pesticide risk reduction and to the proper functioning of pesticide regulatory systems that could be undermined in case of non-compliance. This document addresses the following areas of the pesticide life-cycle:

- $\quad$ Manufacturing and product integrity;

- $\quad$ Distribution (including transportation and sale);

- $\quad$ Product use;

- $\quad$ Product storage; and

- $\quad$ Container recycling and disposal.

\section{www.oecd.org/env/pesticides}

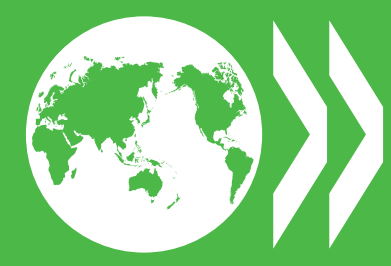

